\title{
Häckningsbiologiska studier av smålommar Gavia stellata på Holmöarna, norra Sverige
}

\section{Breeding biology of the Red-throated Loon Gavia stellata on the Holmöarna Archipelago, Northern Sweden}

\author{
Christer Olsson', Jan Pettersson² \& Frank Johansson ${ }^{3}$ \\ 'Sofiehemsvägen 76A, 907 38, Umeå, Sweden | olssoncito@hotmail.com ² Kåtorp 203, 38692 Färjestaden, Sweden | \\ jan@jpfagelvind.se ${ }^{3}$ Department of Ecology and Genetics, Uppsala University, SE-751 05 Uppsala, Sweden | \\ frank.johansson@ebc.uu.se
}

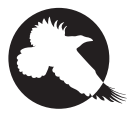

THE AIM of this study was to estimate number of breeding pairs, breeding success, and distance to fishing areas in a population of the Red-throated Loon Gavia stellata on two of the main islands in the Holmöarna Archipelago in the northern part of the Baltic Sea, Sweden. Potential breeding waters were surveyed during seven years, 2010-2015 and 2019. Red-throated Loons appeared in 43 of the 135 lakes of sufficient size on the islands, and the population was estimated to $25-35$ pairs, or about $2 \%$ of the Swedish population. The mean size of lakes with breeding pairs was $1.6 \mathrm{ha}$, and these lakes had an average of $82 \%$ water surface without vegetation ( $18 \%$ vegetation cover). The mean breeding success was low, 0.30 chicks per pair and year, and at least during one year, chicks were produced in only 20 ( $47 \%)$ of the surveyed lakes. The average distance between the nesting waters and the fishing areas for 17 studied pairs was $1.8 \mathrm{~km}$. We discuss the characteristics of suitable nesting waters as well as the factors contributing to the low reproduction.

Keywords: breeding success | Baltic Sea| predation | Common Crane Grus grus | Red-throated Diver

\section{Introduktion}

Smålommen (figur 1) har en utbredning som täcker hela norra halvklotets barrskogsområde (Rizzolo m. fl. 2020). Den europeiska populationen, exklusive Ryssland och
Grönland, uppskattas till $7000-13$ ooo par (BirdLife International 2015) och i Sverige uppskattas antalet par till 1600 (Ottosson m. fl. 2012). Populationen bedöms 
som livskraftig i Europa (BirdLife International 2015, 2020). Beståndsutvecklingen i Sverige följer en svagt uppåtgående trend, medan ungfågelsproduktionen visar en nedåtgående trend (Eriksson 2019). Det är därför viktigt att vi har kunskap om vilka miljövariabler som påverkar val av häckningsplats, samt häckningsframgång, hos smålom. Syftena med denna studie var att undersöka val av häckningssjö, häckningsframgång samt avstånd till födosöksplatser i en population på Holmöarna i norra Sverige.

Holmöarna är en ögrupp belägen i Norra Kvarken (figur 2) och avdelar Norra Kvarken in Västra respektive Östra Kvarken. I Holmöarna ingår öarna Holmön och Ängesön, vilka tillsammans uppgår till en areal av 48 kvadratkilometer. Dessa två öar hyser sedan årtionden en av landets tätaste populationer av smålom (Pettersson \& Olsson 2015). Under de inventeringar av arten som bedrivits i ögruppen 2010-2019 har stammen legat på i storleksordningen 25-35 revirhävdande par (Pettersson \& Olsson 2015). Smålommen häckar inom ögruppen mestadels i små skogstjärnar, som nästan undantagslöst är fiskfria. Eftersom arten i vuxen ålder lever nästan uteslutande av fisk (Rizzolo m. fl. 2020), flyger den under häckningstiden flera dagliga turer mellan häckningstjärnen och fiskevattnen, vilka kan ligga upp till 10 kilometer från boplatsen, ibland längre.

Holmöarnas naturreservat omfattar cirka $60 \%$ av ögruppens totala landareal. Ögruppens strandområden karakteriseras av en snabb landhöjning på ungefär $0,85 \mathrm{~cm} / \mathrm{a}$, vilket betyder att lagunartade vatten avsnörs, där betingelser för bl.a. häckande smålommar kan utvecklas. Skogsbruk har inte förekommit sedan åtminstone 1980 (Länsstyrelsen i Västerbottens län 2015). Detta har medfört att många potentiellt lämpade

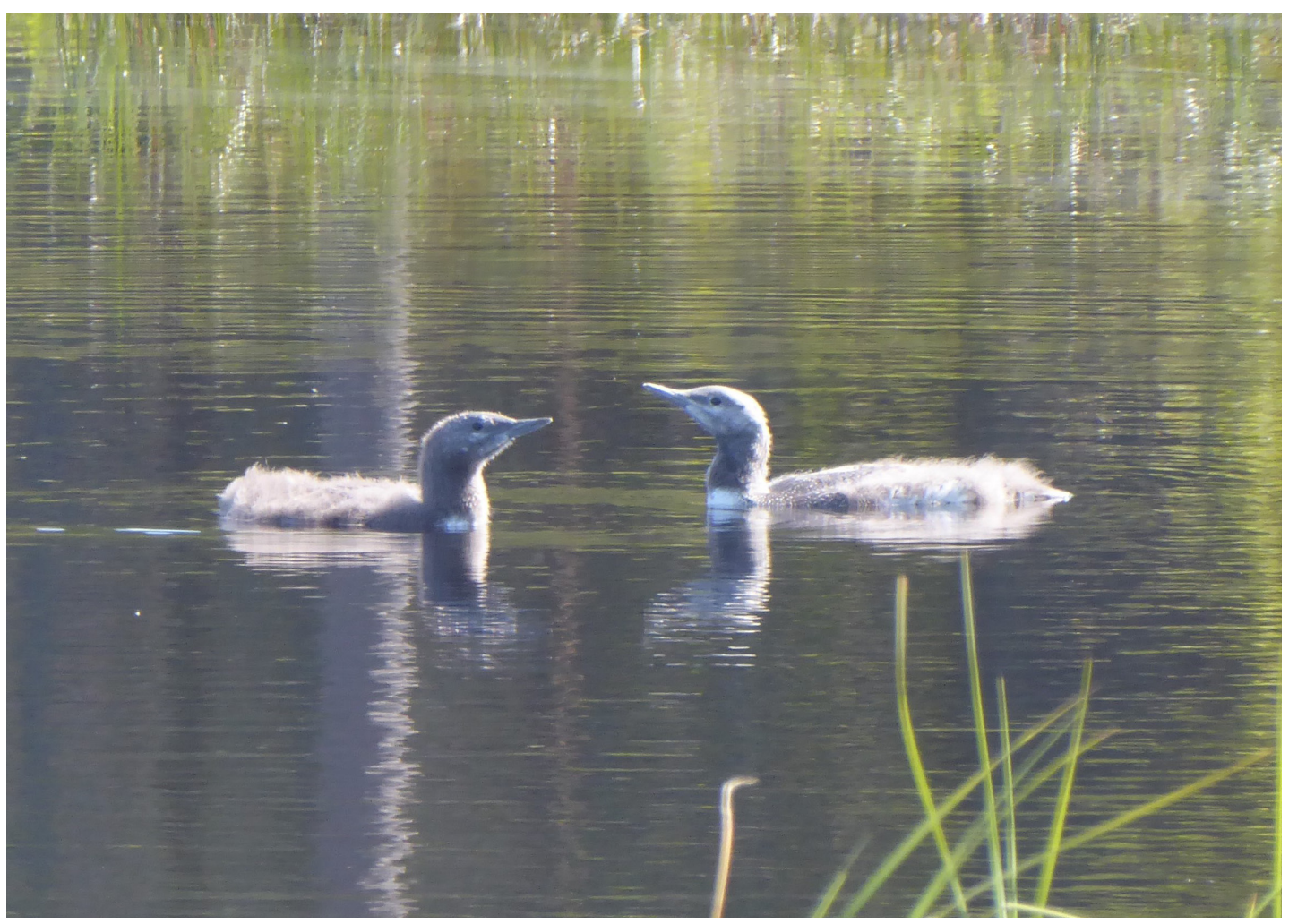

FIGUR 1. Två stora smålomsungar Gavia stellata i den mycket grunda tjärnen Västerön i början av juli 2019. Detta är den tjärn där flest stora ( $\geq 2 / 3$ av fullvuxen storlek) ungar (sju stycken) har producerats under de sju inventeringsåren.

- Two largely full-grown young Red-throated Loons Gavia stellata in the very shallow Lake Västerön at the beginning of July 2019. This is the lake where the highest number of large offspring (grown to $\geq 2 / 3$ of the full size) were found during the seven years of study (seven offspring in total). 


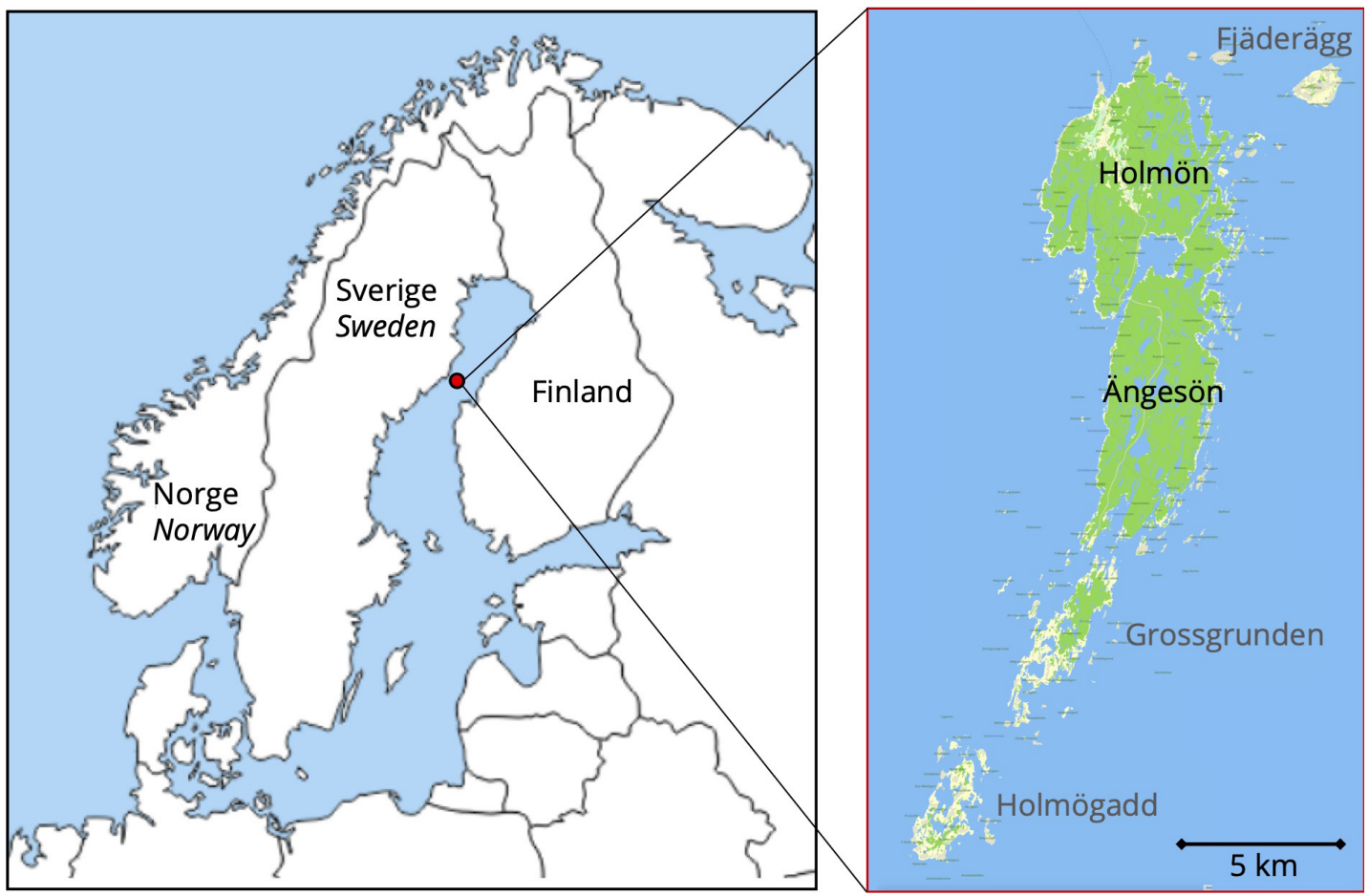

FIGUR 2. Karta över norra Europa, där den röda pricken visar Holmöarnas geografiska läge. Detaljkartan (vars källmaterial är från Eniro) visar Holmöarna, där Holmön och Ängesön hyser häckningsvatten för smålommar Gavia stellata och är de öar som studerats.

- Map of Northern Europe, with the red dot indicating the location of the Holmöarna Archipelago. The detailed map (whose source material is from Eniro) shows the Holmöarna Archipelago, in which the islands Holmön and Ängesön hold breeding lakes for Red-throated Loons Gavia stellata, and which were our study area.

smålomstjärnar inom reservatet inte kommer ifråga framgent som häckningslokaler för arten, dels på grund av att de är omgivna av högvuxen skog, men också för att de saknar lämpliga boplatser, där små, isolerade häckningsöar med rik vegetation torde vara de lämpligaste för arten (Skyllberg m. fl. 1999).

Smålommen har sannolikt en lång historia som häckfågel i Holmögruppen. Flera av ögruppens invatten är mycket grunda, vilket medför att några av de tjärnar där häckning skedde på 1960-talet numer i stort sett är uttorkade och närmast liknar våtmyrar. Ett par andra lokaler, som för 50 år sedan var grunda, djupt inskurna havsvikar, har numer avsnörts på grund av landhöjningen och bildat lämpliga häckningstjärnar för arten. En första undersökning av ögruppens häckfåglar inleddes 1966 av Häger (1968) och höll på fram till 1968. Från denna tidpunkt finns endast en specificerad uppgift om den dåtida smålomsförekomsten i ögruppen: "Observerad ett flertal gånger både på Holmön och
Ängesön. Ett par som med största sannolikhet häckade påträffades i en liten tjärn en halv kilometer söder om Kontviken 14.6 1966." (Häger 1968).

Två heltäckande häckfågelinventeringar har gjorts av hela ögruppens fågelfauna (förutom på fågelskären), 1973 och 1996 (Länsstyrelsen i Västerbottens län 1974, 1997). Det är dock mycket svårt att beräkna antalet par smålom utifrån dessa inventeringsresultat, eftersom överflygande lommar har räknats ihop med stationära exemplar i sjöarna. Nämnas kan att det 1973 noterades 32 exemplar i 17 olika kilometerrutor, medan det 1996 noterades 188 exemplar i 48 olika kilometerrutor, vilket onekligen borde tyda på en rejäl ökning som ligger i linje med en generell trend från 1975 och framåt, enligt Svensk Fågeltaxerings sommarpunktrutter (figur $20 \mathrm{i}$ Green m. fl. 2020).

I övrigt finns från 1970-talet fram till 1991 endast enstaka noteringar om artens häckning i ögruppen, av mer slumpvis funna fåglar: Två häckningar rapporterades 
från Holmön 1989 (Västerbottens Ornitologiska Förenings rapportkommitté 1990). Fyra säkra och tre troliga häckningar rapporterades i Holmögruppen 1990 (Västerbottens Ornitologiska Förenings rapportkommitté 1991). Som ett led i den heltäckande sjöinventeringen av Umeå kommun gjordes 12-14 juni 1992 en heltäckande häckfågelinventering av samtliga invatten i ögruppen. Utifrån resultaten bedömdes då 21 par av smålom ha påbörjat häckning (Umeå kommuns miljökontor 2005).

Åren 2001-2004 genomfördes noggranna inventeringar av samtliga potentiella lokaler för arten på Holmön och Ängesön (Lindblom 2003a, 2003b, 2004). Inventeringen 2001 var främst inriktad på att besöka sjöar med tidigare känd smålomsförekomst, men flera par hittades under den inventeringen även i sjöar där arten inte tidigare rapporterats. Stationära par fanns 2001 i 24 sjöar, 15 par kunde konstateras gå till häckning och ytterligare fem par gjorde häckningsförsök. Endast två par lyckades få ut var sin unge. Det ger o,1 ungar per häckande par (Lindblom 2003a). Vid en inventering 2002 besöktes 135 sjöar, vilket resulterande i 15 par, varav elva gick till häckning, och av dessa fick fem par ut totalt åtta ungar. Tre par fick två ungar och två par var sin unge. Det ger 0,73 ungar per fastställd häckning eller 0,53 ungar per stationärt par. (Lindblom 2003a). Året därpå fanns par med lyckad häckning i åtta sjöar, vilka totalt fick 11 ungar (tre tvåungskullar). Därtill fanns 13 sjöar med häckningsförsök samt två sjöar med stationärt par. Det ger 0,52 ungar per häckande par (Lindblom 2003b). Smålomsinventeringen i ögruppen 2004 gav 14 stationära par/häckningsförsök på Holmön med endast fem ungar som resultat, medan nio stationära par på Ängesön producerade sju ungar, vilket ger en summa på 23 par eller 0,52 ungar per stationärt par (Lindblom 2004). I en nyligen publicerad studie fann Lehtonen (2016) att antalet ungar per par var o,35 på Holmöarna i ett urval av nio sjöar där smålom häckade. Denna studies fann också att sjöar som låg när havet och hade en låg kvot mellan sjöyta/sjöstrandkant hade en högre häckningsframgång. Vår studie skiljer sig från Lehtonens (2016) genom att vi har inkluderat ytterligare två år och att vi undersöker hur de abiotiska sjömiljövariablerna påverkar häckning för i sjöar där det häckade smålom.

Syftet med denna inventering var att undersöka smålomspopulationens storlek på Holmön och Ängesön, dess häckningsframgång och olika miljövariabler som kan påverka häckningarna, samt avståndet till fiskeplatser i havet.

\section{Material och metoder}

\section{INVENTERINGAR}

Inventeringar utfördes på Holmön och Ängesön (de två stora huvudöarna i Holmögruppen) åren 2010-2015 samt 2019. En standardiserad inventeringsmetod, beskriven av Eriksson (2019), tillämpades under samtliga av de sju inventeringsåren. Metoden passar väl för Holmöarna, som har ett mycket stort antal lämpliga häckningslokaler, spridda över en tämligen stor yta. Cirka 135 möjliga häckningsplatser för smålommar finns i ögruppen, innefattande alla invatten som har en yta som överstiger $15 \times 15$ m (eller $225 \mathrm{~m}^{2}$ ) och är så belägna att de erbjuder en trädfri inflygningssträcka på minst $40 \mathrm{~m}$ - annars kan smålommarna få svårt att landa och starta där. Nämnas bör att inventeringarna utförts enbart på de två huvudöarna Holmön och Ängesön. Enstaka och tillfälliga häckningar lär ryktesvis ha skett ett par av åren 2010-2019 på Grossgrunden, men dessa ligger utanför våra inventeringar.

Vid första besök, som gjordes under perioden 10-25 maj, fick samtliga av de 135 sjöarna ett besök för att konstatera om där fanns något par smålom som med stor säkerhet kunde anses vara revirhävdande. Vid osäkerhet gjordes ett andra besök (även det under perioden 10-25 maj) för att bringa klarhet kring smålommens häckningsförhållanden just i det vattnet det specifika året. Med få undantag var de 135 tänkbara häckningsplatserna lättöverskådliga, med få möjligheter för ett par smålommar eller en ruvande faggel att undgå upptäckt. Därtill var tuvan som utgjorde boplats i regel densamma mellan åren. I de få sjöar som var rika på vegetation gjordes en särskilt ingående granskning via en rundvandring av sjön.

Om en ruvande faggel hittades, eller någon adult fågel visade oro vid besök nummer två, gjordes en tredje inventeringsrunda vid just den sjön under perioden 5-20 augusti. Det samma gällde om det sågs ungar som hade en storlek som var mindre än två tredjedelar av de vuxna fåglarnas. Sågs däremot en eller två ungar i sjön (som regel tillsammans med en eller två föräldrar) vilka hade en storlek som översteg två tredjedelar av de vuxnas, ansågs häckningen som lyckad och inget mer besök gjordes vid just det vattnet det året. 
Om inga smålommar återfanns, eller adulta fåglar utan ungar låg på vattnet utan tecken på särskild oro, vid tredje besöket ansågs häckningen vara misslyckad. Om en ruvande fågel (sena omläggare) eller liten unge sågs vid besök nummer tre gjordes ett fjärde besök, fram till det att ett avslut kunde göras. Dessa sena besök har skett under perioden 25 augusti- 5 september.

För jämförelse redovisar vi också fynd från 1992 års inventering (Olsson 1992), trots att endast ett junibesök per sjö då genomfördes och inga uppskattningar av häckningsframgång gjordes. Men å andra sidan blev ögruppen då helinventerad. 1992 års data ingår inte i vår analys.

\section{MILJÖVARIABLER OCH HÄCKNINGAR}

För att få ett mått på vilka miljövariabler som kan tänkas påverka smålommens häckning uppskattades följande: sjöyta, andel vegetation i sjön (andel klarvattenyta), antal stora $\left(\geq 10 \mathrm{~m}^{2}\right)$ öar, antal små $\left(<10 \mathrm{~m}^{2}\right)$ öar, kortaste avstånd mellan häckningssjö och havet. Dessutom uppskattade vi två häckningsvariabler: antalet par per sjö och antalet stora ungar per sjö i de inventerade vattnen. Medelvärdet under de sju åren användes för häckningsvariablerna. I sjöar där smålom inte hittades uppskattades inga miljövariabler. Materialet analyserades med en multipel regression med framåtval som elimineringsprincip (Minitab 2010), och en analys kördes för varje häckningsvariabel. Eftersom andel vegetation i sjöarna var skevt fördelat, med många sjöar som hade mycket lite vegetation, logaritmerade vi denna variabel innan vi körde analysen.

\section{FISKEPLATSER}

Riktade studier gjordes för att undersöka var de häckande smålommarna hade sina fiskeplatser. De utfördes under sammanlagt 28 dagar under perioden 6 juli- 5 augusti följande år: 2012 (8 dagar), 2013 (7 dagar), 2014 (5 dagar) och 2015 (8 dagar). Fältarbetet omfattade främst sjöar där smålommarna hade ungar, eftersom de då mer frekvent ger sig ut på flygturer från sina häckningstjärnar till fiskeplatserna i havet. Första året genomfördes studierna även vid några sjöar där häckningarna misslyckats, men eftersom detta gav så få resultat, ändrades metoden från 2013 till att endast genomföras i sjöar med ungar.

En person bevakade häckningstjärnen och ringde, när en adult smålom lättade för att bege sig ut på en fisketur, omedelbart person nummer två, som var placerad vid kusten, och angav i vilken riktning lommen flög. Innan detta kunde inledas studerades i vilken huvudsaklig riktning de flög ut mot havet. Därefter drogs en vektorlinje upp och person nummer två placerade sig vid den strandlinje där de fåglar som givit sig av beräknades komma ut vid havsstranden. Efter det att observatören ute vid kusten blivit uppringd höjde denne omedelbart beredskapen och spanade efter flygande smålom på väg ut till havs i angiven riktning.

Resultat erhölls från sammanlagt 17 olika häckningssjöar och de respektive parens fiskeplatser. Antalet resultat från varje sjö/fiskeplats varierade från 3 till 23 (kartlagda flygningar från häckningstjärn till observerad fiskeplats i Norra Kvarken). Med hjälp av lämpligt kartmaterial från Eniro prickades sedan varje fiskeplats ut som kunnat knytas till ett specifikt par. Därefter ritades de geometriska figurer ut (cirklar, ellipser eller romber) som bäst stämde överens med utbredningarna av de observerade fiskeplatserna i havet. För att beräkna avstånden mellan häckningssjö och fiskeplats mättes därefter, med hjälp av kartmaterial, de kortaste och längsta noterade avstånden mellan dessa två komponenter. Därutöver summerades avstånden på alla de flygsträckor som uppmätts från varje enskild sjö till de noterade fiskeplatserna och dividerades med antalet observerade flygningar för att få fram ett medelvärde.

\section{Resultat}

Tabell 1 beskriver i siffror och korta termer miljövariabler för de 43 olika häckningsvattnen. De varierar i storlek mellan 0,3 och 6,4 ha, med en medelstorlek om 1,6 ha. Utbredningen av vegetationsfria klarvatten varierar mellan 10 och $97 \%$ för de olika sjöarna, med i medeltal 82 \% klarvattenyta. Antalet större öar i häckningsvattnen som består av så pass fast mark att de kan anses bära ett smålomsbo uppgår i medeltal till 1,2 (o-5) per tjärn. De mindre, tänkbara häckningsöarnas antal uppgår i medeltal till 3,6 per tjärn (o-11).

Smålom hittades i 43 av 135 sjöar och antalet smålommar och ungar ges i tabell 2. Det var emellertid en ojämn fördelning av sjöarna med avseende på ungproduktionen. I 23 sjöar ( $53 \%$ ) producerades överhuvudtaget inga ungar, och i flertalet av de övriga sjöarna var ungproduktionen låg, med en ungproduktion under det intervall om $0,8-0,9$ ungar per par och år som bedömts 
TABELL 1. Samtliga sjöar där smålom Gavia stellata inlett häckning under minst ett av de sju häckningsåren. Ytareal avser hur stor klarvattenytan är vid normalvattenstånd, klarvatten anger andelen av ytarealen som består av helt vegetationsfritt vatten. Antal öar anges uppdelat på större $\left(\geq 10 \mathrm{~m}^{2}\right)$ respektive små $\left(<10 \mathrm{~m}^{2}\right)$ öar som hyser tillräckligt fast mark för att kunna bära ett smålomsbo med ruvande fåglar. Enstaka stenblock eller andra formationer som är olämpliga att ligga på för en ruvande smålom har ej inkluderats. Vegetationen förekommer i form av täta bestånd (t. ex. bladvass Phragmites australis) eller i glesa bestånd (t. ex. starr Carex sp.),

- Lakes in which the Red-throated Loon Gavia stellata has initiated breeding during at least one of the seven years of the study. Surface area is at normal water level, open water describes the proportion of the surface area that is without vegetation. The number of islets is divided across large $\left(\geq 10 \mathrm{~m}^{2}\right)$ and small $\left(<10 \mathrm{~m}^{2}\right)$ islets that hold ground that is firm enough to carry a nest of the Red-throated Loon. Note that single rocks or other structures that are not suitable for a loon nest are not included. The vegetation occurs as dense stands (e.g. beds of common reed Phragmites australis) or sparse stands (e.g. Carex sp.).

\begin{tabular}{|c|c|c|c|c|c|c|}
\hline $\begin{array}{l}\text { Sjö } \\
\text { Lake }\end{array}$ & $\begin{array}{l}\text { Avstånd till } \\
\text { havet }(\mathrm{km}) \\
\text { Distance to } \\
\text { sea }(\mathrm{km})\end{array}$ & $\begin{array}{l}\text { Ytareal } \\
\text { (ha) } \\
\text { Surface } \\
\text { area (ha) }\end{array}$ & $\begin{array}{l}\text { Klar- } \\
\text { vatten } \\
\text { Open } \\
\text { water }\end{array}$ & $\begin{array}{l}\text { Större } \\
\text { öar } \\
\text { Larger } \\
\text { islets }\end{array}$ & $\begin{array}{l}\text { Små } \\
\text { öar } \\
\text { Small } \\
\text { islets }\end{array}$ & $\begin{array}{l}\text { Ytandel täckt: vegetation (och sten om signifikant) } \\
\text { Surface cover: vegetation (and rocks if significant) }\end{array}$ \\
\hline Abborrkrokgraven & 1,66 & 1,0 & $70 \%$ & 0 & 8 & $\begin{array}{l}30 \%: \text { starr Carex sp. } \\
30 \% \text { : sedge Carex sp. }\end{array}$ \\
\hline $\begin{array}{l}\text { NV NW Bränn- } \\
\text { fjärden }\end{array}$ & 1,62 & 2,0 & $65 \%$ & 0 & 3 & $\begin{array}{l}35 \% \text { : starr, vattenklöver Menyanthes trifoliata } \\
35 \% \text { : sedge, bogbean Menyanthes trifoliata }\end{array}$ \\
\hline Frickgraven & 1,35 & 2,3 & $95 \%$ & 1 & 5 & $\begin{array}{l}5 \% \text { : starr, vattenklöver, hästsvans Hippuris vulgaris } \\
5 \% \text { : sedge, bogbean, common mare's-tail Hippuris } \\
\text { vulgaris }\end{array}$ \\
\hline Halvtjärnen & 0,35 & 0,8 & $65 \%$ & 1 & 4 & $\begin{array}{l}35 \% \text { : starr, vattenklöver } \\
35 \% \text { : sedge, bogbean }\end{array}$ \\
\hline Halörsgraven & 1,01 & 5,4 & $95 \%$ & 1 & 2 & $\begin{array}{l}5 \% \text { : starr, hästsvans, vattenklöver } \\
5 \% \text { : sedge, common mare's-tail, bogbean }\end{array}$ \\
\hline Hamntutterdiket & 0,25 & 0,5 & $97 \%$ & 0 & 0 & $\begin{array}{l}3 \%: \text { starr, vattenklöver } \\
3 \%: \text { sedge, bogbean }\end{array}$ \\
\hline Hasabacktjärnen & 0,95 & 0,7 & $85 \%$ & 2 & 4 & $\begin{array}{l}5 \% \text { : starr, vattenklöver, gul näckros Nuphar lutea } \\
5 \% \text { : sedge, bogbean, yellow water-lily Nuphar lutea }\end{array}$ \\
\hline Jonskärsviken & 0,87 & 5,3 & $97 \%$ & 0 & 0 & $\begin{array}{l}3 \% \text { : starr, topplösa Lysimachia thyrsiflora, } \\
\text { sprängört Cicuta virosa } \\
3 \% \text { : sedge, tufted loosestrife Lysimachia thyrsiflora, } \\
\text { European water-hemlock Cicuta virosa }\end{array}$ \\
\hline $\begin{array}{l}\text { Tjärn SO SE Klafsän- } \\
\text { get }\end{array}$ & 1,36 & 0,4 & $65 \%$ & 1 & 11 & $\begin{array}{l}35 \% \text { : mossrika flarkar, starr } \\
35 \% \text { : moss-rich flarks, sedge }\end{array}$ \\
\hline Kopptjärnarna & 1,08 & 2,3 & $95 \%$ & 5 & 7 & $\begin{array}{l}5 \% \text { : starr, vattenklöver } \\
5 \% \text { : sedge, bogbean }\end{array}$ \\
\hline Kroksandgraven & 1,07 & 1,2 & $95 \%$ & 0 & 2 & $\begin{array}{l}5 \%: \text { starr, vattenklöver } \\
5 \%: \text { sedge, bogbean }\end{array}$ \\
\hline Lill-Fanasjön & 1,42 & 2,9 & $90 \%$ & 2 & 5 & $\begin{array}{l}5 \% \text { : starr, hästsvans, vattenklöver } \\
5 \% \text { : sedge, common mare's-tail, bogbean }\end{array}$ \\
\hline Lill-Kvistersviken & 1,05 & 1,2 & $65 \%$ & 0 & 8 & $\begin{array}{l}35 \% \text { : starr, vattenklöver } \\
35 \% \text { : sedge, bogbean }\end{array}$ \\
\hline Långrevgraven & 1,70 & 1,6 & $80 \%$ & 1 & 2 & $\begin{array}{l}15 \%: \text { starr, vattenklöver } \\
15 \% \text { : sedge, bogbean }\end{array}$ \\
\hline Långsjön & 2,26 & 2,4 & $95 \%$ & 4 & 2 & $\begin{array}{l}5 \%: \text { starr } \\
5 \%: \text { sedge }\end{array}$ \\
\hline Långviken, Holmön & 1,49 & 1,9 & $97 \%$ & 0 & 1 & $\begin{array}{l}3 \%: \text { starr, pors Myrica gale, vattenklöver } \\
3 \% \text { : sedge, bog-myrtle Myrica gale, bogbean }\end{array}$ \\
\hline $\begin{array}{l}\text { Långviken, } \\
\text { Ängesön }\end{array}$ & 1,48 & 2,5 & $90 \%$ & 2 & 0 & $\begin{array}{l}10 \%: \text { starr, vattenklöver } \\
10 \%: \text { sedge, bogbean }\end{array}$ \\
\hline $\begin{array}{l}\text { Mellersta Flagg- } \\
\text { diket }\end{array}$ & 0,74 & 0,5 & $85 \%$ & 2 & 3 & $\begin{array}{l}15 \% \text { : starr, hästsvans, vattenklöver } \\
15 \% \text { : sedge, common mare's-tail, bogbean }\end{array}$ \\
\hline
\end{tabular}


TABELL 1 fortsatt continued

\begin{tabular}{|c|c|c|c|c|c|c|}
\hline $\begin{array}{l}\text { Sjö } \\
\text { Lake }\end{array}$ & $\begin{array}{l}\text { Avstånd till } \\
\text { havet }(\mathrm{km}) \\
\text { Distance to } \\
\text { sea }(\mathrm{km})\end{array}$ & $\begin{array}{l}\text { Ytareal } \\
\text { (ha) } \\
\text { Surface } \\
\text { area (ha) }\end{array}$ & $\begin{array}{l}\text { Klar- } \\
\text { vatten } \\
\text { Open } \\
\text { water }\end{array}$ & $\begin{array}{l}\text { Större } \\
\text { Öar } \\
\text { Larger } \\
\text { islets }\end{array}$ & $\begin{array}{l}\text { Små } \\
\text { Öar } \\
\text { Small } \\
\text { islets }\end{array}$ & $\begin{array}{l}\text { Ytandel täckt: vegetation (och sten om signifikant) } \\
\text { Surface cover: vegetation (and rocks if significant) }\end{array}$ \\
\hline Mellersta Skatasjön & 0,55 & 1,0 & $97 \%$ & 0 & 0 & $\begin{array}{l}3 \%: \text { starr, vattenklöver } \\
3 \%: \text { sedge, bogbean }\end{array}$ \\
\hline Nörd-Skatasjön & 0,61 & 1,7 & $90 \%$ & 0 & 2 & $\begin{array}{l}10 \% \text { : starr, bladvass Phragmites australis } \\
10 \%: \text { sedge, common reed Phragmites australis }\end{array}$ \\
\hline Nörsinggraven & 1,37 & 6,4 & $80 \%$ & 2 & 2 & $\begin{array}{l}20 \%: \text { starr, stora stenar } \\
20 \%: \text { sedge, large rocks }\end{array}$ \\
\hline Rentjärnen & 2,16 & 0,3 & $95 \%$ & 1 & 1 & $\begin{array}{l}5 \% \text { : starr, vattenklöver, gul näckros } \\
5 \% \text { : sedge, bogbean, yellow water-lily }\end{array}$ \\
\hline Risstrandsjön & 2,19 & 2,5 & $80 \%$ & 2 & 10 & $\begin{array}{l}20 \%: \text { starr (täta tuvor och solitära plantor) } \\
20 \%: \text { sedge (dense tufts and solitary stands) }\end{array}$ \\
\hline $\begin{array}{l}\text { Tjärn NO NE } \\
\text { Risstrandsjön }\end{array}$ & 1,53 & 0,4 & $50 \%$ & 2 & 10 & $\begin{array}{l}50 \% \text { : mossrika tuvor, starr } \\
50 \% \text { : moss-rich flarks, sedge }\end{array}$ \\
\hline Sekasttjärnen & 0,56 & 0,7 & $97 \%$ & 1 & 4 & $\begin{array}{l}3 \%: \text { starr } \\
3 \%: \text { sedge }\end{array}$ \\
\hline Skärnäsögergraven & 1,11 & 1,1 & $80 \%$ & 0 & 4 & $\begin{array}{l}20 \% \text { : starr, vattenklöver } \\
20 \% \text { : sedge, bogbean }\end{array}$ \\
\hline Spikgraven & 1,33 & 0,7 & $85 \%$ & 1 & 3 & $\begin{array}{l}15 \%: \text { starr, vattenklöver } \\
15 \% \text { : sedge, bogbean }\end{array}$ \\
\hline Storstendiket & 0,58 & 1,7 & $97 \%$ & 2 & 2 & $\begin{array}{l}3 \%: \text { starr, stora stenar } \\
3 \%: \text { sedge, large rocks }\end{array}$ \\
\hline Storåvättan & 2,39 & 1,7 & $80 \%$ & 1 & 4 & $\begin{array}{l}20 \% \text { : starr, vattenklöver, bladvass } \\
20 \% \text { : sedge, bogbean, common reed }\end{array}$ \\
\hline Sör-Jonasdiket & 0,37 & 0,7 & $95 \%$ & 0 & 3 & $\begin{array}{l}5 \% \text { : starr, vattenklöver } \\
5 \% \text { : sedge, bogbean }\end{array}$ \\
\hline Sör-Skatasjön & 0,64 & 1,0 & $97 \%$ & 1 & 0 & $\begin{array}{l}3 \%: \text { starr, vattenklöver } \\
3 \% \text { : sedge, bogbean }\end{array}$ \\
\hline Trapptjärnen & 0,24 & 0,3 & $80 \%$ & 0 & 1 & $\begin{array}{l}20 \%: \text { starr, gul näckros } \\
5 \% \text { : sedge, yellow water-lily }\end{array}$ \\
\hline Vedaögertjärnen & 0,26 & 1,0 & $85 \%$ & 0 & 3 & $\begin{array}{l}15 \%: \text { starr } \\
15 \%: \text { sedge }\end{array}$ \\
\hline Villtjärnen & 0,77 & 1,5 & $90 \%$ & 0 & 6 & $\begin{array}{l}10 \%: \text { starr } \\
10 \%: \text { sedge }\end{array}$ \\
\hline Västerön & 0,36 & 0,8 & $15 \%$ & 3 & 10 & $\begin{array}{l}85 \% \text { : starr, vattenklöver } \\
85 \% \text { : sedge, bogbean }\end{array}$ \\
\hline Västra Flaggdiket & 0,52 & 0,8 & $65 \%$ & 2 & 7 & $\begin{array}{l}35 \% \text { : starr, vattenklöver } \\
35 \% \text { : sedge, bogbean }\end{array}$ \\
\hline Västra Gersjön & 1,21 & 2,9 & $90 \%$ & 5 & 3 & $\begin{array}{l}10 \% \text { : starr, hästsvans } \\
10 \% \text { : sedge, common mare's-tail }\end{array}$ \\
\hline Västra Ögerviken & 3,02 & 0,8 & $97 \%$ & 1 & 1 & $\begin{array}{l}3 \%: \text { starr } \\
3 \%: \text { sedge }\end{array}$ \\
\hline Ånörsgraven & 0,29 & 1,3 & $75 \%$ & 0 & 1 & $\begin{array}{l}25 \% \text { : starr, hästsvans } \\
25 \% \text { : sedge, common mare's-tail }\end{array}$ \\
\hline Östra Flaggdiket & 0,89 & 0,6 & $90 \%$ & 2 & 3 & $\begin{array}{l}10 \%: \text { starr, vattenklöver } \\
10 \%: \text { sedge, bogbean }\end{array}$ \\
\hline Östra Gersjön & 0,97 & 3,1 & $10 \%$ & 3 & 5 & $\begin{array}{l}90 \% \text { : starr, mosstuvor } \\
90 \% \text { : sedge, tufts of moss }\end{array}$ \\
\hline Östra Taskhamnen & 0,36 & 1,7 & $90 \%$ & 1 & 2 & $\begin{array}{l}10 \%: \text { starr, stora stenar } \\
10 \%: \text { sedge, large rocks }\end{array}$ \\
\hline
\end{tabular}


TABELL 1 fortsatt continued.

\begin{tabular}{|c|c|c|c|c|c|c|}
\hline Sjö & $\begin{array}{l}\text { Avstånd till } \\
\text { havet }(\mathrm{km})\end{array}$ & $\begin{array}{l}\text { Ytareal } \\
\text { (ha) }\end{array}$ & $\begin{array}{l}\text { Klar- } \\
\text { vatten }\end{array}$ & $\begin{array}{l}\text { Större } \\
\text { Öar }\end{array}$ & $\begin{array}{l}\text { Små } \\
\text { öar }\end{array}$ & Ytandel täckt: vegetation (och sten om signifikant) \\
\hline Lake & $\begin{array}{l}\text { Distance to } \\
\text { sea }(\mathrm{km})\end{array}$ & $\begin{array}{l}\text { Surface } \\
\text { area (ha) }\end{array}$ & $\begin{array}{l}\text { Open } \\
\text { water }\end{array}$ & $\begin{array}{l}\text { Larger } \\
\text { islets }\end{array}$ & $\begin{array}{l}\text { Small } \\
\text { islets }\end{array}$ & Surface cover: vegetation (and rocks if significant) \\
\hline Östra Ögerviken & 2,34 & 1,5 & $97 \%$ & 1 & 3 & $\begin{array}{l}3 \% \text { : starr, hästsvans } \\
3 \% \text { : sedge, common mare's-tail }\end{array}$ \\
\hline
\end{tabular}

TABELL 2. Sjöar där smålom Gavia stellata återfunnits under något eller flera av de sju åren under omständigheter som starkt indikerar att häckning åtminstone påbörjats. I de fall där så skett, utan att den resulterat i någon unge, anges i tabellen antal par (ợ). När häckningen varit lyckad anges hur många ungar (juv.) per häckning som uppnått minst 2/3 storlek av vuxen fågels. Även fynd från 1992 års inventering har här medtagits, trots att endast ett junibesök per sjö då gjordes, men ögruppen blev då å andra sidan helinventerad. Medelantal $(\overline{\mathbf{x}})$, summa $(\Sigma)$. - Lakes in which Red-throated Loons Gavia stellata have been found during at least one of the seven years of study under circumstances that strongly indicate breeding. In cases when the breeding has not resulted in any young, only the number of pairs (ơ) is indicated. In cases of successful breeding, the number of young (juv.) at a size of at least $2 / 3$ of an adult is stated. In addition to our study period, data from a survey in 1992 is included, when lakes were only visited once in June, but when all lakes of the archipelago

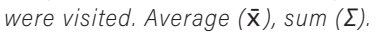

\begin{tabular}{|c|c|c|c|c|c|c|c|c|c|c|}
\hline \multirow{2}{*}{$\begin{array}{l}\text { Sjö } \\
\text { Lake }\end{array}$} & \multirow[b]{2}{*}{$1992 *$} & \multicolumn{7}{|c|}{ Undersökningsperiod | Study period } & \multirow{2}{*}{$\begin{array}{l}\text { År } \\
\text { Year }\end{array}$} & \multirow{2}{*}{$\begin{array}{l}\bar{x} \text { ungar/år } \\
\bar{x} \text { young/year }\end{array}$} \\
\hline & & 2010 & 2011 & 2012 & 2013 & 2014 & 2015 & 2019 & & \\
\hline Abborrkrokgraven & & $1 \stackrel{+}{0}$ & & $1 \stackrel{+}{*}$ & $1 \overbrace{}^{7}$ & 1 ợ 1 juv. & 1 ơ 1 juv. & $1 \stackrel{9}{o^{*}}$ & 6 & 0,33 \\
\hline $\begin{array}{l}\text { NV NW Bränn- } \\
\text { fjärden }\end{array}$ & 1 ơ $^{\top}$ & & 1 q $^{\top}$ & 1 ơ $^{\top}$ & 1 ơ $^{\top}$ & 1 ơ 1 juv. & $1 o^{7}$ & 1 o $^{7}$ & 6 & 0,17 \\
\hline Frickgraven & $1 \stackrel{+}{0}$ & 1 ơ & 1 ơ & 1 ơ & 1 ơ 1 juv. & 1 ơ & 1 ơ & 1 ơ & 7 & 0,14 \\
\hline Halvtjärnen & & & & 1 q $^{7}$ & & $1 \stackrel{+}{T}$ & 1 ọt $^{T}$ & & 3 & 0,00 \\
\hline Halörsgraven & & & & $1 \overbrace{}^{7}$ & & & $1 \overbrace{}^{x}$ & & 2 & 0,00 \\
\hline Hamntutterdiket & & & & & & 1 ọt $^{7}$ & & & 1 & 0,00 \\
\hline Hasabacktjärnen & 1 ơ $^{x}$ & 1 ợ 1 juv. & 1 ơ $^{x}$ & 1 ơ $^{7}$ & 1 ơt $^{x}$ & & 1 ợ 2 juv. & 1 ơ $^{x}$ & 7 & 0,43 \\
\hline Jonskärsviken & & $20^{x}$ & 1 ơ $^{x}$ & 1 ơt $^{x}$ & & 1 ơ $^{7}$ & 1 ơ $^{x}$ & 1 ơ $^{x}$ & 6 & 0,00 \\
\hline $\begin{array}{l}\text { Tjärn SO SE } \\
\text { Klafsänget }\end{array}$ & & & & & 1 ơ $^{7}$ & & & & 1 & 0,00 \\
\hline Kopptjärnarna & $10^{x}$ & & & & 1 ơt $^{x}$ & & & & 1 & 0,00 \\
\hline Kroksandgraven & 1 ơ $^{x}$ & 1 ọ $^{\pi}$ & $1 \overbrace{}^{7}$ & $1 o^{7}$ & 1 ọt $^{7}$ & 1 ợ 2 juv. & $1 o^{\top}$ & 1 ợ 2 juv. & 7 & 0,57 \\
\hline Lill-Fanasjön & 1 ơ $^{x}$ & 1 ơ $^{7}$ & $1 o^{7}$ & 1 ợ 1 juv. & 1 ơ 2 juv. & 1 q $^{7}$ & $1 o^{x}$ & $1 \mathrm{ot}^{x}$ & 7 & 0,43 \\
\hline Lill-Kvistersviken & & 1 ơt $^{*}$ & 1 ợ $^{7}$ & $1 o^{7}$ & 1 ợ 2 juv. & 1 ơt $^{7}$ & $1 \overbrace{+}^{T}$ & & 6 & 0,33 \\
\hline Långrevgraven & & 1 ơ $^{x}$ & $1 q^{7}$ & & $1 \overbrace{}^{7}$ & 1 q $^{7}$ & 1 q $^{x}$ & $1 \overbrace{}^{\pi}$ & 6 & 0,00 \\
\hline Långsjön & $2 o_{+}^{7}$ & 1 ọ $^{\pi}$ & $1 \stackrel{+}{0}$ & & 1 ọ $^{7}$ & 1 ọt $^{7}$ & $1 \overbrace{+}^{\pi}$ & 1 ot $^{7}$ & 6 & 0,00 \\
\hline Långviken, Holmön & $10^{x}$ & & & & & 1 ơt $^{7}$ & $1 \overbrace{+}^{T}$ & $1 \stackrel{+}{T}$ & 3 & 0,00 \\
\hline $\begin{array}{l}\text { Långviken, } \\
\text { Ängesön }\end{array}$ & 1 ơ $^{x}$ & 1 ơ $^{\top}$ & 1 q $^{\pi}$ & $1 o^{n}$ & $1 \overbrace{+}^{7}$ & 1 q $^{7}$ & $1 o^{7}$ & 1 ợ 1 juv. & 7 & 0,14 \\
\hline $\begin{array}{l}\text { Mellersta } \\
\text { Flaggdiket }\end{array}$ & & 1 ơ 1 juv. & $1 \overbrace{}^{7}$ & & 1 ợ 2 juv. & 1 ơ $^{7}$ & 1 ơ 1 juv. & 1 o $^{7}$ & 7 & 0,67 \\
\hline Mellersta Skatasjön & $1 \stackrel{+}{0}$ & & & & & $1 \stackrel{9}{q}$ & & & 1 & 0,00 \\
\hline Nörd-Skatasjön & & $1 \stackrel{+}{0}$ & & & 1 ọ $^{7}$ & 1 ọ $^{7}$ & & $1 \stackrel{+}{T}$ & 4 & 0,00 \\
\hline Nörsinggraven & & $1 o^{*}$ & 1 ơ $^{x}$ & 1 ơ $^{x}$ & 1 ơt $^{7}$ & 1 ơ $^{x}$ & 1 ơ $^{x}$ & & 6 & 0,00 \\
\hline Rentjärnen & 1 o $^{*}$ & $1 \overbrace{}^{\pi}$ & $1 \overbrace{}^{7}$ & $1 o^{x}$ & $1 \overbrace{}^{7}$ & $1 \overbrace{}^{7}$ & $1 \overbrace{}^{x}$ & 1 ot $^{\pi}$ & 7 & 0,00 \\
\hline
\end{tabular}


TABELL 2 fortsatt continued

\begin{tabular}{|c|c|c|c|c|c|c|c|c|c|c|}
\hline \multirow{2}{*}{$\begin{array}{l}\text { Sjö } \\
\text { Lake }\end{array}$} & \multirow[b]{2}{*}{$1992 *$} & \multicolumn{7}{|c|}{ Undersökningsperiod | Study period } & \multirow{2}{*}{$\begin{array}{l}\text { År } \\
\text { Year }\end{array}$} & \multirow{2}{*}{$\begin{array}{l}\bar{x} \text { ungar/år } \\
\bar{x} \text { young/year }\end{array}$} \\
\hline & & 2010 & 2011 & 2012 & 2013 & 2014 & 2015 & 2019 & & \\
\hline Risstrandsjön & $1 \overbrace{}^{\pi}$ & $\begin{array}{c}2 \stackrel{+}{7}^{\star} \\
2 \text { juv. **}\end{array}$ & $\begin{array}{c}2 \text { ơ }^{*} \\
2 \text { juv. ** }\end{array}$ & $2 \overbrace{}^{\pi}$ & $2 q^{n}$ & $1 \stackrel{9}{t}$ & $1 \stackrel{+}{9}$ & $1 o^{\pi}$ & 7 & 0,29 \\
\hline $\begin{array}{l}\text { Tjärn NO NE } \\
\text { Risstrandsjön }\end{array}$ & & $1 q^{\pi}$ & & & $1 \stackrel{\text { ot }}{\prime \prime}$ & & & & 1 & 0,00 \\
\hline Sekasttjärnen & & & & & $1 \stackrel{+}{t}$ & & $1 \overbrace{}^{\pi}$ & & 2 & 0,00 \\
\hline Skärnäsögergraven & & $1 q^{7}$ & $1 q^{7}$ & & & & & & 2 & 0,00 \\
\hline Spikgraven & & $1 q^{\pi}$ & $1 q^{\top} 1$ juv. & $1 \overbrace{}^{\pi}$ & $1 q^{\top} 1$ juv. & $1 \stackrel{9}{q}$ & $1 \stackrel{q}{x}^{x} 1$ juv. & $1 q^{\pi} 2$ juv. & 7 & 0,71 \\
\hline $\begin{array}{l}\text { Stor-Klubbtjärnen, } \\
\text { Ö E Ängesön }\end{array}$ & $1 q^{n}$ & & & & & & & & - & - \\
\hline Storstendiket & & $1 \stackrel{9}{7}$ & & $1 \stackrel{+}{7}$ & & & & & 2 & 0,00 \\
\hline Storåvättan & $1 q^{7}$ & $1 q^{\pi}$ & $1 q^{x} 1$ juv. & $1 q^{7}$ & $1 q^{7}$ & 1 ơ 1 juv. & $1 \mathscr{q}^{7}$ & $1 \mathscr{q}^{7}$ & 7 & 0,29 \\
\hline Sör-Jonasdiket & & & & & & & & $1 \overbrace{}^{\pi}$ & 1 & 0,00 \\
\hline Sör-Skatasjön & $1 \overbrace{}^{\pi}$ & $1 q^{7}$ & $1 \overbrace{}^{\pi}$ & $1 \overbrace{}^{\pi}$ & 1 ơ $^{\pi}$ & $1 q^{\pi}$ & $1 \overbrace{}^{\pi}$ & & 6 & 0,00 \\
\hline $\begin{array}{l}\text { Tomastjärnen, } \\
\text { SV SW Holmön }\end{array}$ & $1 \stackrel{9}{7}$ & & & & & & & & - & - \\
\hline Trapptjärnen & & $1 q^{n}$ & & $1 \overbrace{}^{n}$ & $1 \stackrel{9}{9}$ & & & & 3 & 0,00 \\
\hline Vedaögertjärnen & & 1 ợ 2 juv. & & 1 ơt $^{7}$ & $2 o^{7}$ & 1 ơ 2 juv. & 1 ot $^{7}$ & $1 \stackrel{9}{*}$ & 6 & 0,67 \\
\hline Villtjärnen & 1 ơ $^{7}$ & 1 ơ 1 juv. & $1 q^{\pi} 2$ juv. & 1 ơ $^{7}$ & 1 ơ $^{7}$ & $1 q^{\prime \prime}$ & & & 5 & 0,60 \\
\hline Västerön & 1 ơ $^{7}$ & & $1 q^{x} 1$ juv. & 1 ợ 1 juv. & $1 q^{x} 2$ juv. & $1 \overbrace{}^{7}$ & $1 q^{x} 1$ juv. & 1 ợ 2 juv. & 6 & 1,17 \\
\hline Västra Flaggdiket & & 1 ơ 1 juv. & 1 ơ $^{7}$ & $1 \stackrel{+}{7}$ & & & 1 ơ $^{x} 2$ juv. & & 4 & 0,75 \\
\hline Västra Gersjön & & $1 \stackrel{+}{7}$ & $1 q^{7}$ & 1 ơ & $1 \stackrel{+}{9}$ & $1 \stackrel{+}{7}$ & 1 ơ 1 juv. & 1 ơ 1 juv. & 7 & 0,29 \\
\hline Västra Ögerviken & & 1 ơ 2 juv. & & & & & & & 1 & 2,00 \\
\hline Ånörsgraven & & 1 ơ $^{7}$ & 1 ơ $^{\top} 1$ juv. & $1 \stackrel{0}{7}$ & 1 ơ 2 juv. & 1 ơ 2 juv. & 1 o $^{\prime}$ & 1 ợ 1 juv. & 7 & 0,86 \\
\hline Östra Flaggdiket & 1 ơ $^{7}$ & 1 ợ 1 juv. & & $1 \mathscr{q}^{7}$ & 1 ơ $^{\top} 1$ juv. & $1 \mathscr{q}^{\prime \prime}$ & $1 \mathscr{q}^{7}$ & 1 ơ $^{7}$ & 6 & 0,33 \\
\hline Östra Gersjön & & $1 q^{n}$ & $1 q^{7}$ & & & $1 \overbrace{}^{7}$ & $1 \overbrace{}^{7}$ & & 4 & 0,00 \\
\hline Östra Taskhamnen & $1 q^{\pi}$ & 1 ơ & & & & $1 \stackrel{+}{\pi}$ & & & 2 & 0,00 \\
\hline Östra Ögerviken & & & $1 q^{x}$ & $1 \stackrel{+}{7}$ & $1 q_{+}^{7}$ & $1 q^{*}$ & $1 \overbrace{}^{N}$ & $1 q^{x}$ & 6 & 0,00 \\
\hline$\Sigma$ par pairs & $21 *$ & 33 & 26 & 28 & 32 & 32 & 30 & 24 & & \\
\hline$\Sigma$ ungar young & & 11 & 8 & 2 & 13 & 9 & 9 & 9 & & \\
\hline $\begin{array}{l}\bar{x} \text { ungar/par, Holmö } \\
\bar{x} \text { young/pair, Holmöc }\end{array}$ & & 0,33 & 0,31 & 0,07 & 0,41 & 0,28 & 0,30 & 0,38 & & \\
\hline $\begin{array}{l}\text { - motsvarande, } \\
\text { Norrlands kustlan } \\
\text { - corresponding, } \\
\text { coastal Norrland }^{+}\end{array}$ & & 0,67 & 0,91 & 0,75 & 0,29 & 0,74 & 0,50 & 0,64 & & \\
\hline $\begin{array}{l}\Sigma \text { lyckade häckningar } \\
\Sigma \text { successful breedings }\end{array}$ & & 9 & 7 & 2 & 8 & 6 & 7 & 6 & & \\
\hline $\begin{array}{l}\text { Andel tvåungskullar } \\
\text { Proportion two- } \\
\text { chick clutches }\end{array}$ & & 0,22 & 0,14 & 0,00 & 0,63 & 0,50 & 0,29 & 0,50 & & \\
\hline $\begin{array}{l}\text { - motsvarande, } \\
\text { Norrlands kustlar } \\
\text { - corresponding, } \\
\text { coastal Norrland }^{+}\end{array}$ & & 0,43 & 0,5 & 0,7 & 0,25 & 0,44 & 0,38 & 0,45 & & \\
\hline
\end{tabular}


* Inventeringen 1992 genomfördes 13-14 juni då, alla invatten i hela Holmögruppen systematiskt inventerades.

* The census in 1992 was carried out 13-14 June, when all lakes of any size were surveyed systematically.

** Två par fick var sin unge i Risstrandsjön 2010 och 2011. Two pairs produced one young each at Lake Risstrandsjön in 2010 and 2011.

† Smålommar häckande på fastlandet, upp till 10 km från stranden (från tabell 4 i Eriksson 2020)

${ }^{t}$ Red-throated Loons breeding on the mainland, up to $10 \mathrm{~km}$ from the coastline (from Table 4 in Eriksson 2020).

vara minimum för att kompensera för den årliga dödligheten (Hemmingsson \& Eriksson 2002).

Medelhäckningsframgången var 0,30 ungar per par och år, vilket är betydligt lägre än det genomsnitt om o,64 ungar per par och år som noterades för smålommar häckande i det norrländska kustlandet (Skyllberg m. fl. 1999), och upp till $10 \mathrm{~km}$ från kusten under samma period (tvåsidigt Wilcoxon-test avseende matchade par, $p=0,03)$. En numerärt stor skillnad vad gäller procentandelen lyckade häckningar med 2 stora ungar, i genomsnitt $33 \%$ per år för Holmöarna, jämfört med $45 \%$ fastlandshäckande smålommar (tabell 2) kunde emellertid inte verifieras med statistisk signifikans (tvåsidigt Wilcoxon-test avseende matchade par, $p=0,47$ ).

Medelstorleken för sjöar med smålom var 1,65 ha ( \pm standardavvikelse 1,37 ha) och medelandel av vegetationstäcket var 17,84 $( \pm 19,55) \%$. Medelantalet små och stora öar i sjöar med smålom var 1,23 ( $\pm 1,31)$ och 3,65 $( \pm 2,98)$. De multipla regressionerna med antalet smålomspar och antalet ungar som responsvariabel behöll tre respektive två variabler i den slutgiltiga modellen (tabell 3). Resultaten visade att andelen vegetation och avstånd till havet hade en statistisk signifikant effekt på antalet häckande smålomspar, men ingen av miljövariablerna påverkade häckningsframgången statistiskt signifikant (tabell 3). En multipel regression med bakåteliminering gav likande resultat.

Figur 3-7 visar var i Östra och Västra Kvarken de häckande smålommarna från 17 olika tjärnar i ögruppen hade sina fiskeplatser. Intervallet för den kortaste sträckan mellan de 17 sjöarna till parens fiskevatten var $0,3-2,5 \mathrm{~km}$, medan intervallet för längsta sträckan var 1,1-3,1 km. Medelavstånden var 0,7-2,7 km. Lägger man samman dessa medeltal făr man fram att medelsträckan som fiskande fåglar från de 17 paren tillryggalägger till sina fiskevatten är 1,8 kilometer $(n=151)$. Flertalet av de undersökta smålomsparen flög den kortast möjliga sträckan från häckningsplatsen till havet (figur 3-7). Vi noterar att storleken på fiskeområdet är korrelerat med antalet fiskeplatsobservationer.

TABELL 3. Resultat för multipla regressioner för antalet par och ungar av smålom Gavia stellata. En variansinflationsfaktor (VIF) om ca 1 innebär låg kollinearitet mellan variablerna, medan ett över 5 innebär hög kollinearitet mellan variablerna. $R^{2}=0,17$ respektive 0,09 för antal par och ungar.

- Results of multiple regressions on the number of pairs and offspring of Red-throated Loon Gavia stellata. A variance inflation factor (VIF) of 1 indicates low multicollinearity among variables, while a value of 5 indicates high multicollinearity. $R^{2}=0.17$ and 0.09 for pairs and young, respectively.

\begin{tabular}{|c|c|c|c|c|c|}
\hline \multirow[b]{2}{*}{$\begin{array}{l}\text { Variabel } \\
\text { Variable }\end{array}$} & \multicolumn{2}{|c|}{ Koefficient Coefficient } & \multirow[b]{2}{*}{$\begin{array}{l}\text { T-värde } \\
\text { T value }\end{array}$} & \multirow[b]{2}{*}{$\begin{array}{l}\text { P-värde } \\
\text { P value }\end{array}$} & \multirow[b]{2}{*}{$\begin{array}{l}\text { VIF } \\
\text { VIF }\end{array}$} \\
\hline & $\begin{array}{l}\text { Estimat } \\
\text { Estimate }\end{array}$ & $\begin{array}{l}\text { Standardfel } \\
\text { Std. Error }\end{array}$ & & & \\
\hline \multicolumn{6}{|l|}{ Smålomspar } \\
\hline Konstant & 0,294 & 0,160 & 1,84 & 0,073 & \\
\hline Stora stenar & $-0,036$ & 0,02 & $-1,76$ & 0,086 & 1,67 \\
\hline Avstånd & 0,16 & 0,07 & 2,13 & 0,039 & 1,05 \\
\hline Vegetation & 0,31 & 0,14 & 2,16 & 0,037 & 1,67 \\
\hline \multicolumn{6}{|l|}{ Ungar } \\
\hline Konstant & 0,25 & 0,13 & 1,94 & 0,060 & \\
\hline Area & $-0,07$ & 0,04 & $-1,74$ & 0,096 & 1,03 \\
\hline Avstånd & 0,12 & 0,09 & $-1,31$ & 0,198 & 1,03 \\
\hline
\end{tabular}

FIGUR 3 (överst nästa sida). Röd pil visar den rutt som de smålommar Gavia stellata på norra delen av Holmön, Västerbotten, som häckar i Lill-Fanasjön flyger för att födosöka (baserat på observationer av 23 födosöksturer; födosöksområde avgränsat av röd polygon). Svarta markeringar visar motsvarande rutt och område för de smålommar som häckar i Västra Gersjön fiskar (4 födosöksturer). Kartmaterial från Eniro.

- (top next page.) The red arrow shows the flight route to the fishing waters (red polygon) for Red-throated Loons Gavia stellata at the northern part of Holmön, northern Sweden, nesting at Lake Lill-Fanasjön (observations of 23 foraging trips). The black markings show the corresponding flight route and fishing waters of Red-throated Loons nesting at Lake Västra Gersjön (4 foraging trips). Map from Eniro. 


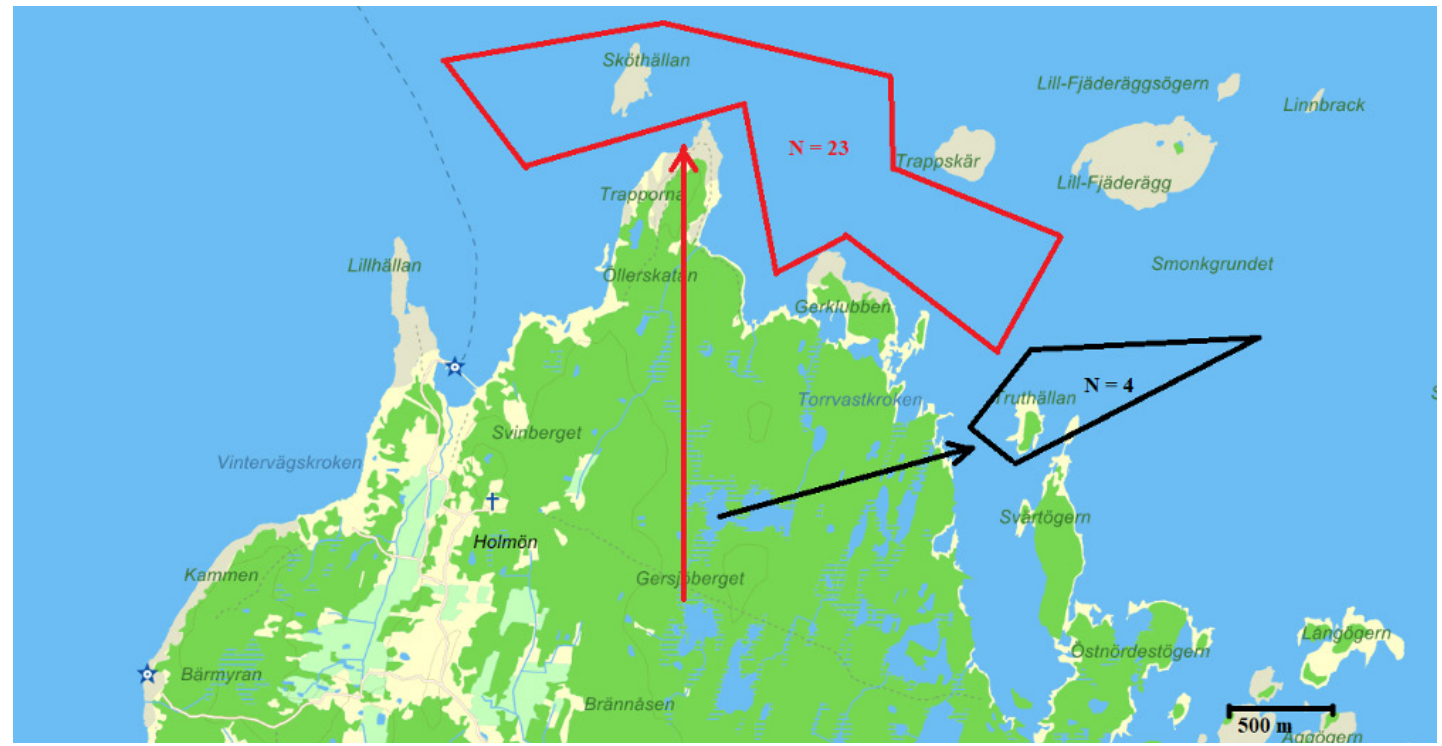

FIGUR 3. Se föregående sida för figurtext. See previous page for caption.

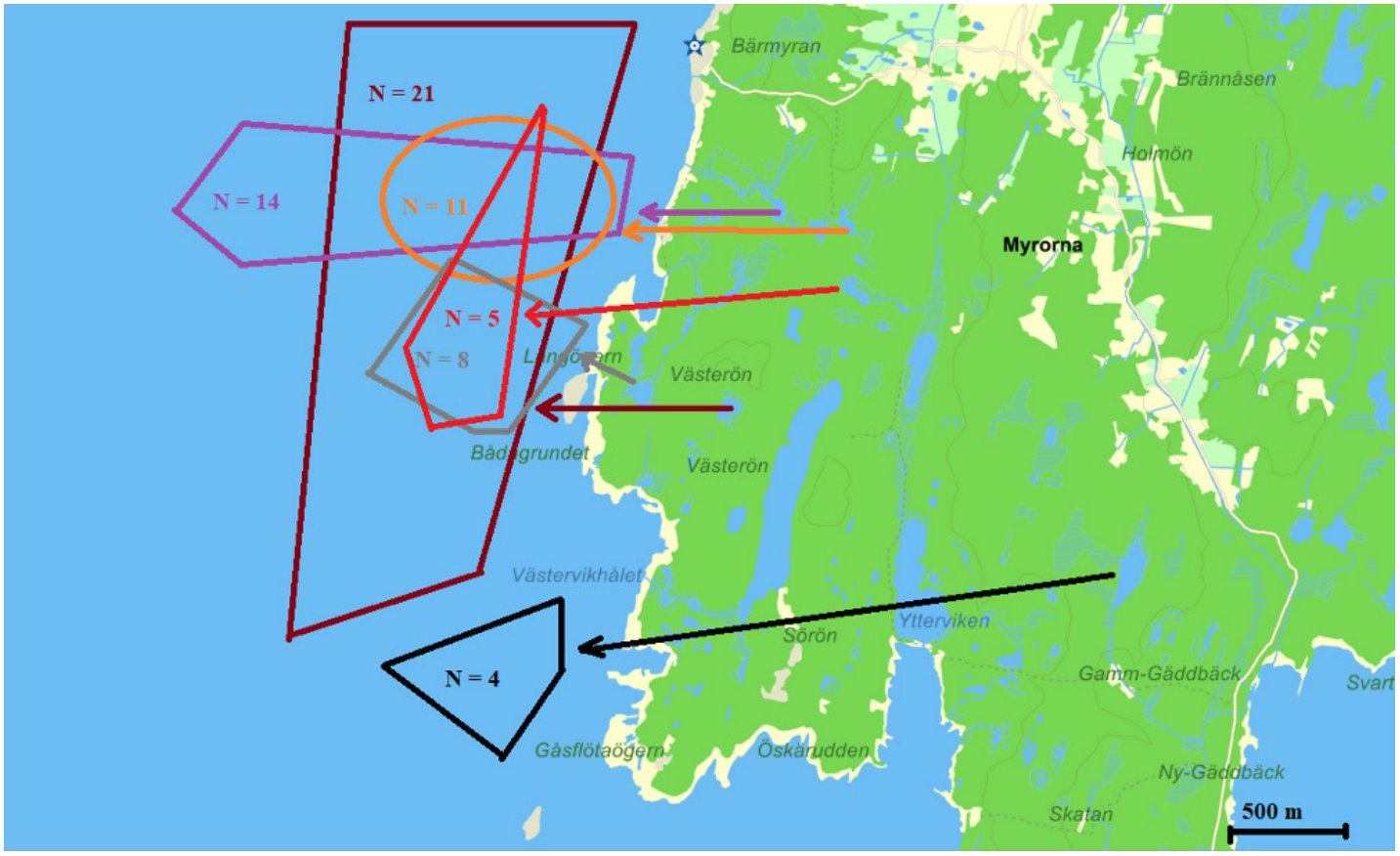

FIGUR 4. I enlighet med figur 3 visar pilar flygrutt från häckningssjö och polygoner fiskevatten. Här visas smålommar Gavia stellata som häckar på sydvästra delen av Holmön, Västerbotten, i sjön Västerön (bruna markeringar, 21 födosöksturer), Västra Flaggdiket (lila markeringar, 14 födosöksturer), Östra Flaggdiket (orange markeringar, 11 födosöksturer), Hasabacktjärnen (röda markeringar, 5 födosöksturer), Vedaögertjärnen fiskar (grå markeringar, 8 födosöksturer) respektive Långsjön (svarta markeringar, 4 födosöksturer). Kartmaterial från Eniro.

- Following Figure 3, arrows indicate flight routes from the breeding lakes and polygons demarcate fishing waters. Here, we show Red-throated Loons Gavia stellata at the southwestern part of Holmön, northern Sweden, nesting in Lake Västerön (brown markings; 21 foraging trips), Lake Västra Flaggdiket (violet markings; 14 foraging trips), Lake Östra Flaggdiket (orange markings; 11 foraging trips), Lake Hasabacktjärnen (red markings; 5 foraging trips), Lake Vedaögertjärnen (grey markings; 8 foraging trips), and finally Lake Långsjön ( $N=4$ foraging trips). Map from Eniro. 


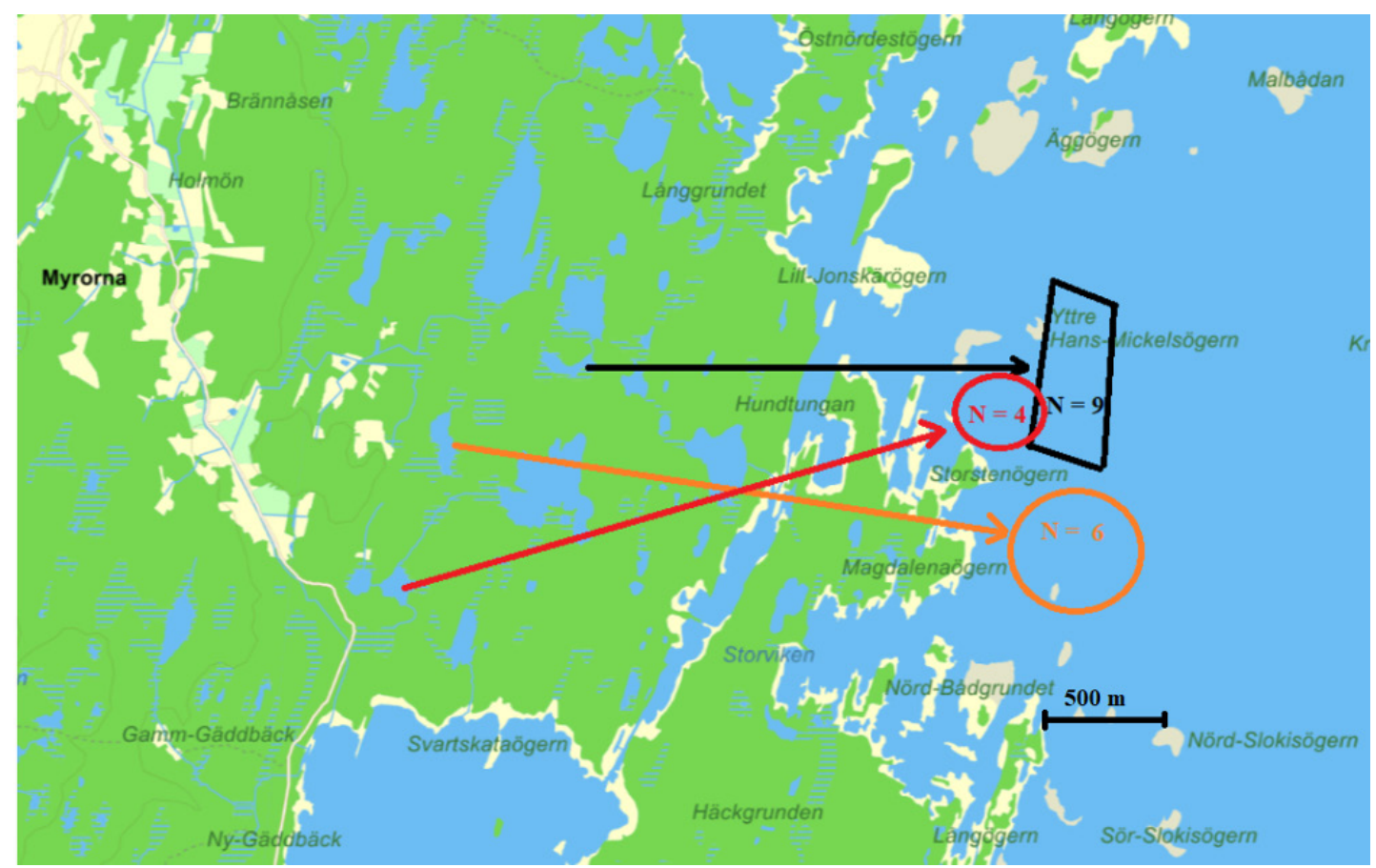

FIGUR 5. I enlighet med figur 3 visar pilar flygrutt från häckningssjö och polygoner fiskevatten. Här visas smålommar Gavia stellata som häckar på sydöstra delen av Holmön, Västerbotten, i Lill-Kvistersviken (svarta markeringar, 9 födosöksturer), Östra Ögerviken (röda markeringar, 4 födosöksturer) respektive Storåvättan (orange markeringar, 6 födosöksturer). Kartmaterial från Eniro.

- Following Figure 3, arrows indicate flight routes from the breeding lakes and polygons demarcate fishing waters. Here, we show Red-throated Loons Gavia stellata at the southeastern part of Holmön, northern Sweden, nesting in Lake Lill-Kvistersviken (black markings; 9 foraging trips), Lake Östra Ögerviken (red markings; 4 foraging trips), and Storåvättan (orange markings; 6 foraging trips). Map from Eniro.

\section{Diskussion}

Medelhäckningsframgången var 0,30 ungar per par och år. Det är betydligt lägre än den nivå på o,64 stora ungar per par och år som noterades för smålommar häckande på det norrländska fastlandet under samma år (tabell 2; Eriksson 2020). Siffrorna kan även jämföras med Skyllberg m. fl. (1999) som erhöll ett resultat om 0,23-0,86 stora ungar per stationärt par i en undersökning som genomfördes under fem säsonger, 1993-1998, på fastlandssidan av Västra Kvarken.

Vi hittade inga samband mellan antalet ungar och de miljövariabler vi mätte i sjöarna, och den ojämna fördelningen mellan sjöar med och utan ungar under sjuårsperioden förblir oförklarad. Även Skyllberg m. fl. (1999) fann att majoriteten av de miljövariabler som de mätte inte påverkade häckningsframgången i sin studie av fastlandshäckande smålommar i samma landskap (Västerbotten), men att andelen av vegetationstäcket på sjön samt mängden växtlighet runt boet hade signifikant positiva effekter på häckningsframgången.

Orsaken till att Skyllberg m. fl. (1999) fann en effekt av vegetationstäckets utbredning i sjön kan vara att det var stor variation inom denna variabel i de vatten som där undersöktes. I åtta (47\%) av deras 17 studerade sjöar bestod sjön helt och hållet av klarvatten. I vår studie uppvisade ingen sjö $100 \%$ klarvattenyta, men 16 (37\%) av 43 sjöar hade en sådan som låg på 95-97\% av sjöns totala yta. I intervallet $65-89 \%$ klarvattenyta noterades $6(35 \%)$ av de 17 sjöar som undersöktes av Skyllberg m. fl. (1999), medan motsvarande tal i denna studie var $24(56 \%)$ av Holmöarnas 43 smålomssjöar. Man kan alltså anse att klarvattenytan som parameter hade en större variation i sjöarna vid Skyllbergs studie, jämfört med vår studie.

Skyllberg m. fl. (1999) fann att antalet stora ungar 
per påbörjad häckning varierade avsevärt mellan de sex undersökningsåren, vilket de menar beror på faktorer som gör sig gällande innan ungarna lämnar redet, således under ruvningstiden och tiden strax efter kläckning. Tänkbara orsaker kan vara att ruvningen avbryts på grund av att vattennivån påtagligt stiger i sjön under ruvningstiden eller att boet prederas.

Trots att vi inte fann något samband mellan de stora ytor av häckningsvattnen som uppvisar vegetationsfritt klarvatten $(82 \%)$ och den låga reproduktionstakten, kan en låg grad av vegetationstäckning av vattnet vara viktig för häckningsframgång, eftersom det i regel finns lite skyddande vegetation att gömma sig i för de små ungarna. Noteras bör att i den tjärn där häckningsframgången varit högst under denna studie (den tjärn som kallas Västerön), består hela $90 \%$ av sjöns yta av skyddande vegetation. Vi kan även notera att antalet häckande par var signifikant positivt korrelerat med mängden vegetation i sjöarna.

I en annan studie på Holmöarna jämförde Lehtonen (2016) miljövariabler mellan sjöar där smålom häckade respektive inte häckade. Lehtonen (2016) hittade inga signifikanta skillnader mellan sjöarna med avseende på miljövariablerna, men fann att sjöar med högre häckningsframgång hade en lägre kvot mellan sjöns area och omkrets och kortare avstånd till havet. Det verkar alltså som om de flesta miljövariabler som uppskattats i Skyllberg m.fl. (1999), Lehtonen (2016) och vår studie har liten betydelse för häckningsframgången.

Andra tänkbara miljöfaktorer som kan tänkas påverka häckningsframgången kan, som antyds av Skyllberg m. fl. (1999), vara predatortrycket. Två av de sannolikt viktigaste predatorerna på ömse sidor av Västra Kvarken är trana Grus grus och havsörn Haliaeetus albicilla - båda arterna häckande i nära anslutning till många av sjöarna på Holmöarna och på fastlandssidan.

Stammen av dessa två potentiella predatorarter har vuxit markant sedan Skyllberg m. fl. (1999) gjorde sina studier. Det gäller inte minst på Holmön och Ängesön, där 68 par tranor med revir kartlades vid häckfågelinventering 2010 (nu sannolikt ännu fler; egna observationer) och åtta revirhävdande par havsörn hittades vid

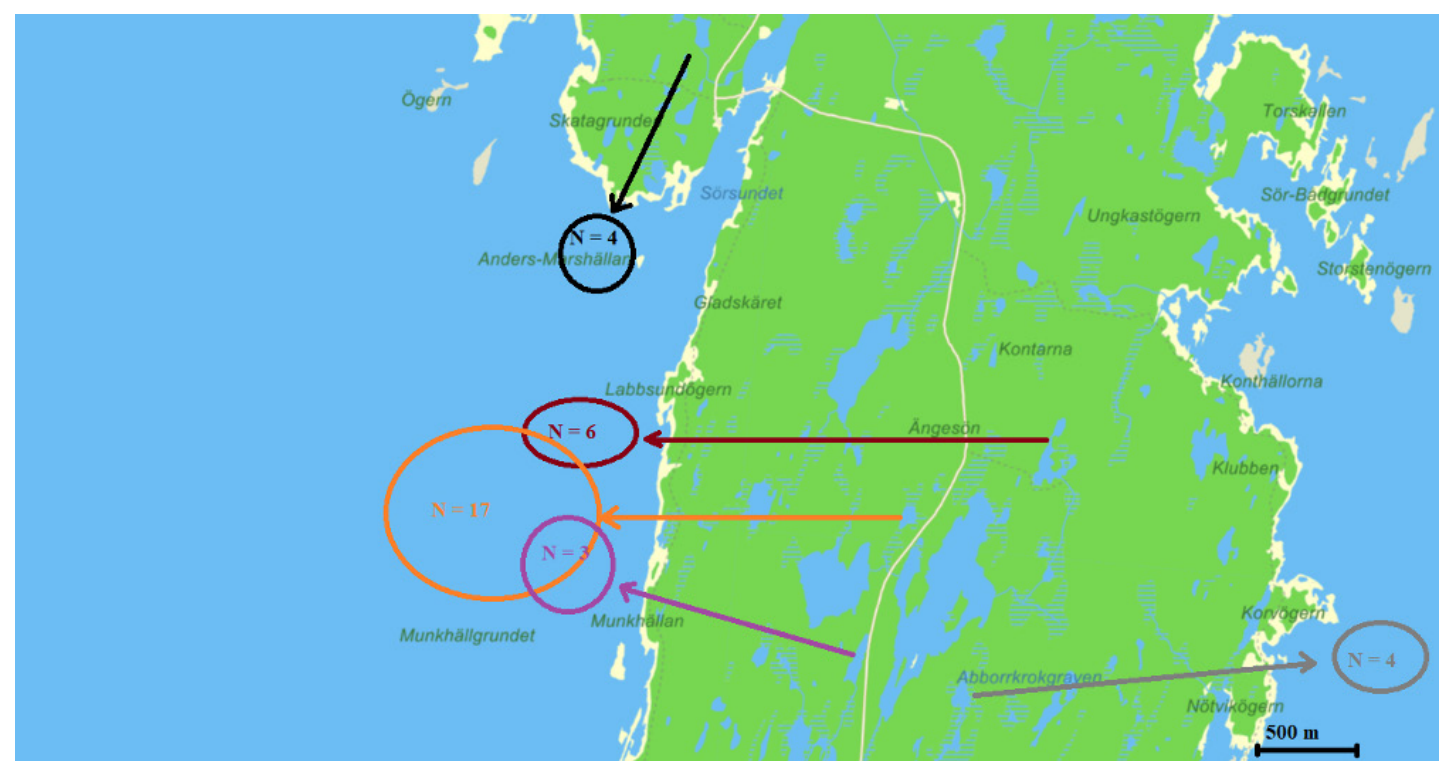

FIGUR 6. I enlighet med figur 3 visar pilar flygrutt från häckningssjö och polygoner fiskevatten. Här visas smålommar Gavia stellata som häckar på norra halvan av Ängesön, Västerbotten, i sjön Sör-Skatasjön (svarta markeringar, 4 födosöksturer), Frickgraven (bruna markeringar, 6 födosöksturer), Spikgraven (orange markeringar, 17 födosöksturer), Kroksandgraven (lila markeringar, 3 födosöksturer) respektive Abborrkrokgraven fiskar (grå markeringar, 4 födosöksturer). Kartmaterial från Eniro.

- Following Figure 3, arrows indicate flight routes from the breeding lakes and polygons demarcate fishing waters. Here, we show Red-throated Loons Gavia stellata at the northern half of Ängesön, northern Sweden, nesting in Lake Sör-Skatasjön (black markings; 4 foraging trips), Lake Frickgraven (brown markings; 6 foraging trips), Lake Spikgraven (orange markings; 17 foraging trips), Lake Kroksandgraven (purple markings; 3 foraging trips), and Lake Abborrkrokgraven (grey markings; 4 foraging trips). Map from Eniro. 
inventering 2015 (egna observationer). Predatortrycket är sannolikt en viktig faktor när det gäller häckningsframgång hos smålommar. Hela $29(67 \%)$ av de 43 sjöar där smålom hyst revir under minst ett år i denna studie ligger mindre än två kilometer från havsörnsbon som hyst häckande par under hela inventeringsperioden. Inga havsörnsattacker noterades emellertid under studien och inga örnar observerades med vuxna eller unga smålommar i klorna. Dock gjorde vi 20 observationer under inventeringens gång av havsörnar som stöttes från träd i kanten av vattendrag där smålommar legat och ruvat (ofta på en liten ö i tjärnen).

Vid nästan alla av de 43 tjärnar/sjöar där smålom noterades hittades även häckande tranor. Fyra fall finns från denna inventering där tranor tagit över de små öar ute i sjön där smålom legat och ruvat föregående år. Noteras bör att tranorna intar sina häckningsplatser redan ett par veckor innan islossningen i början av maj (egna observationer). Smålommarna ankommer till häckningsvattnen när de blir isfria och om tranor gått till häckning ruvar dessa då redan ägg (egna observationer). Inte heller för tranans del finns observationer av fåglar som tagit ägg eller små ungar av smålom, men mer övertygande indikationer har noterats på andra håll (t. ex. Dahlén \& Eriksson 2002). Med utgångspunkt i tranans breda födospektrum måste dock denna, i ögruppen mycket talrika, art föras högt upp på listan över tänkbara predatorer på Holmöarnas smålommar.

Också i andra undersökningar har man bedömt att bopredation är en viktig orsak till misslyckade häckningar. I en studie i Alaska berodde hela $80 \%$ av de misslyckade häckningarna på försvunna ägg (Eberl \& Picman 1989). Samma studie visade att i åtta av de nio fall, där ungar försvann från häckande smålomspar, var ungarna mindre än en vecka gamla när så skedde.

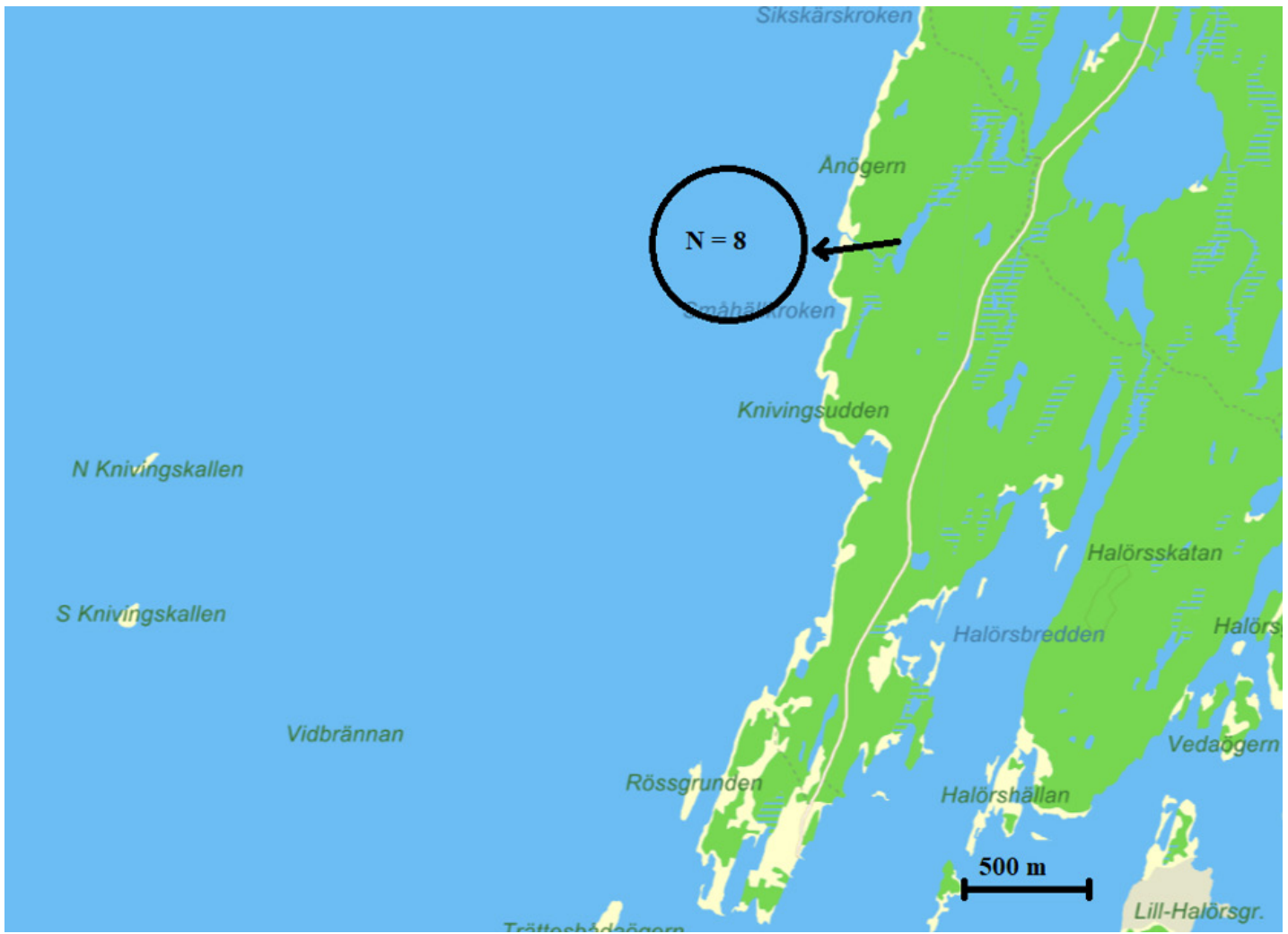

FIGUR 7. Svart pil visar den rutt som de smålommar Gavia stellata som häckar i Ånörsgraven på sydvästra delen av Ängesön, Västerbotten, flyger för att födosöka i fiskevatten (svart polygon), baserat på observationer av 8 födosöksturer. Kartmaterial från Eniro.

- The black arrow shows the flight route to the fishing waters (black polygon) for Red-throated Loons Gavia stellata nesting at Lake Ånörsgraven in the southwestern part of Ängesön, northern Sweden (observations of 8 foraging trips). Map from Eniro. 
Även i undersökningar på Shetlandsöarna har man noterat att huvuddelen av alla häckningar misslyckas under ruvningsstadiet, och att predation är en huvudorsak (Hulka 2010), men att förlust av stora ungar är förhållandevis ovanligt (Bundy 1976). Likaledes visade Dahlén \& Eriksson (2002) att bopredation är en huvudorsak till misslyckade häckningar i det svenska smålomsbeståndet. Slutligen, de rikstäckande uppföljningarna av lommarnas häckningsutfall inom ramen för Projekt Lom (https://projektlom.birdlife.se/) visar att en negativ trend i smålommens ungproduktion till stor del kan kopplas till händelser under ruvningen (Eriksson 2019). Kanske kan de uteblivna sambanden mellan undersökta miljöfaktorer och ungproduktion förklaras av ett allt överskuggande predationstryck som slår likartat över flertalet av sjöarna?

Sammantaget bidrar dessa resultat till en ökad misstänksamhet mot tranan som en betydande predator. Tyvärr började de starka misstankarna mot tranan som en viktig predator av till storleken små smålomsungar och smålomsägg väckas först under det andra året av denna studie, varför någon typ av metod som tog hänsyn till detta inte ingick i den här aktuella metodiken.

Andra tänkbara predatorer i ögruppen är korp Corvus corax, kråka C. corone cornix, duvhök Accipiter gentilis, rödräv Vulpes vulpes samt mink Neovison vison. Att de fyra förstnämnda har relativt svaga stammar i ögruppen indikeras av de ytmässigt heltäckande inventeringarna av Holmön och Ängesön 2010 (Pettersson \& Olsson 2015). Det troliga är att duvhöken numer är utgången bland häckfåglarna på Holmön och Ängesön.
Ett par häckade på Ängesön fram till åtminstone 2011. Minken finns spridd i ögruppen främst på öar i skärgården runt Holmöarna. Under inventeringarna 2012-2019 gjordes endast två observationer av mink mindre än en kilometer från tjärn med ruvande smålom.

En annan potentiell faktor som skulle kunna påverka häckningsframgång är variationer i vattenstånd mellan år och mellan sjöar. Eftersom Holmöarna är flacka och många av sjöarna ligger när havet borde nederbörd och vattenstånd påverka vattennivån i sjöarna. Tyvärr har vi inte mätt vattenstånd i vår studie men vi rekommenderar att framtida studier mäter denna variabel, särskilt i områden med flack topografi.

Lommarna kläcker i regel två ungar, men det är vanligt att bara en av dem blir flygg, och vi vet från andra undersökningar att ungarnas överlevnad till stor del beror på hur bra föräldrafåglarna lyckas med matningsbestyren (t. ex. Okill \& Wanless 1990, Eberl \& Picman 1993, Rizzolo m. fl. 2014). Därför finns det anledning att också undersöka andelen ungkullar med två stora ungar, eftersom det ger en indikation på hur bra föräldrafåglarna lyckas med matningsbestyren. Vi fann ingen statistiskt signifikant skillnad mellan i medeltal $33 \%$ per år för Holmöarna och $45 \%$ för fastlandshäckande smålommar längs Norrlandskusten (tabell 2; Eriksson 2020). Nivån för fastlandslommarna (45\%) ligger nära andelen lyckade häckningar med två ungar som noterades av Skyllberg m. fl. (1999), med totalt 15 (54\%) av 28 framgångsrika häckningar. Rimligtvis har födotillgången varit tämligen jämbördig för de smålommar som fiskar i västligaste delen av Norra

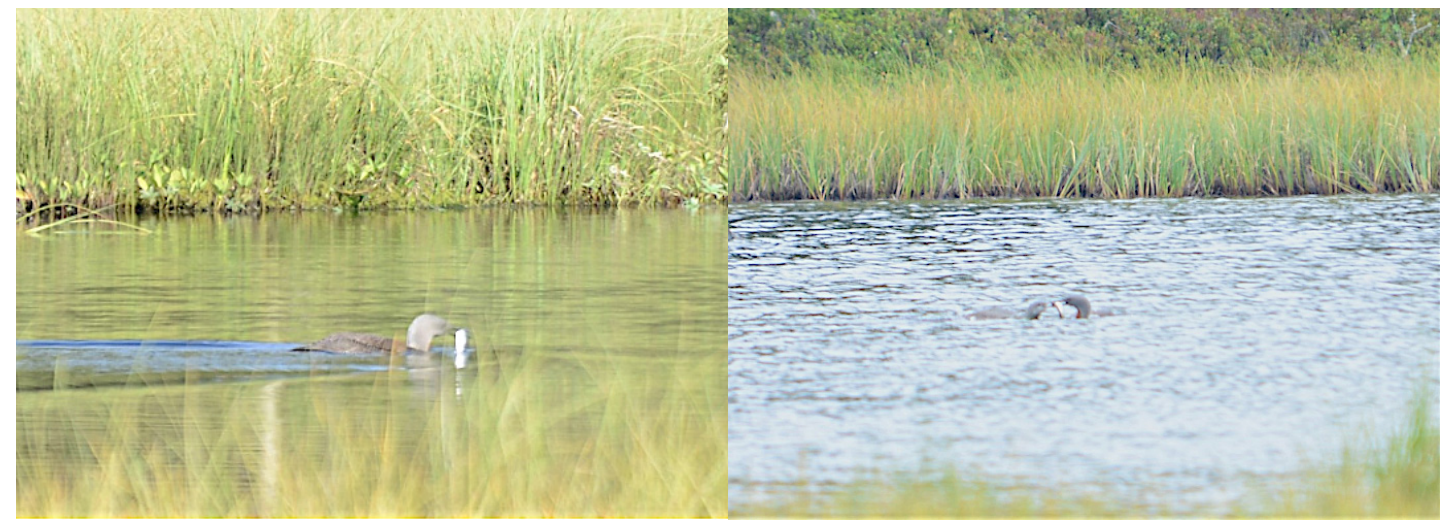

FIGUR 8. Fältfoton av adulta smålommar Gavia stellata som återvänder till häckningstjärnen med strömming Clupea harengus från havet för att mata sina ungar.

- Field documentation of adult Red-throated Loons Gavia stellata returning to the breeding lake with Atlantic herring Clupea harengus to feed young 
Kvarken och de som fiskar längre österut i samma vatten (runt Holmöarna).

Fotobevis för att strömming utgör en viktig smålomsföda på Holmöarna erhölls från åtminstone nio av häckningssjöarna i denna studie, där ungarna blev matade med strömmingar Clupea harengus (figur 8). Vattnen väster och sydväst om Berguddens fyr på västra Holmön anses av hävd vara bland de bästa för strömmingsfiske i hela Norra Kvarken bland äldre Holmöfiskare. Detta kan troligen förklara de många lyckade födosöken som kartlades i detta område. Som ett exempel kan nämnas att från det att en vuxen faggel lämnade sin häckningstjärn, Västra Flaggdiket, tog det vid ett tillfälle som klockades endast 2 minuter och 50 sekunder innan fågeln var åter i sin tjärn med en fisk till ungen.

Avståndet mellan häckningstjärn och fiskevattnet inom Holmögruppen ligger $i$ vår studie av 17 studerade tjärnar på i medeltal 1,8 kilometer. Skillnaderna mellan kortaste avståndet till fiskevattnet (300 m) och det längsta som uppmättes $(3,1 \mathrm{~km})$ är såpass små att de sannolikt inte har någon större inverkan på häckningsframgången. Det är dock påtagligt att flertalet av smålommarna i de undersökta sjöarna flög den kortaste sträckan från häckningsvattnet till havet utanför (figur 3-7). Vi vet inte mycket om var fiskevattnen för de par som hävdat revir i de övriga 26 invattnen som ingick i studien ligger, men sannolikt hade det framräknade medelavståndet inte påverkats särskilt mycket om vi hade haft tillgång till data även från dem, med tanke på ögruppens geografiska utseende. Lehtonen (2016) fann att häckningsframgången var negativt korrelerat med avstånd till havet (dock en svag effekt), dvs. det var större häckningsframgång om sjöarna låg närmare havet. Vi fann inte något sådant samband. Det enda samband vi fann med avseende på avstånd till havet var ett svagt positivt samband mellan avståndet till havet och antalet häckande par (tabell 3).

Mänsklig störning är en faktor som sannolikt är av försumbar betydelse när gäller Holmöarnas smålommar. Den stora majoriteten av sjöarna ligger mer än en kilometer från närmaste bebodda hus och lika långt från närmaste farbara väg. Endast två sjöar ligger mindre än hundra meter från den bilväg som går i nord-sydlig riktning längs Holmön och Ängesön, nämligen Spikgraven och Kroksandgraven. Båda dessa sjöar återfinns emellertid bland dem som har producerat flest stora ungar och därtill haft revirhävdande par samtliga av de sju inventeringsåren (tabell 2). Nämnas bör att trafiken på Holmöarna är mycket gles och att vägarnas kvalitet inte tillåter högre fart. Det bör också nämnas att lommar på platser långt ifrån mänsklig aktivitet kan bli väldigt skärrade de gånger människor uppträder nära en häckning. Man kan alltså också tänka sig att det är just den enstaka besökaren till lomvattnen på Holmöarna som orsakar en låg häckningsframgång. Sådana enstaka störningar kan göra att boet lämnas öppet för predation.

Smålommarnas val av häckningsvatten på Holmöarna tycks vara ganska stabil. Jämför vi inventeringarna 13-14 juni 1992 med de som har utförts 2010-2019, låt vara med skilda metoder, ser vi att det finns endast en tjärn vardera på Holmön och Ängesön där arten hyste revir 1992 men inte något av åren 2010-2019. Bilden skiljer sig alltså från vad som gäller för fastlandshäckande smålommar häckande i betydligt glesare tätheter, där det finns en dynamik över tid med övergivande av häckningsplatser, nyetableringar och återetableringar (Eriksson \& Åhlund 2013).

Av de 43 vatten där smålom hävdat revir 2010-2019 är det $25(58 \%)$ av dem som hyst arten åtminstone fem av de sju inventeringsåren. Detta, liksom den ojämna fördelningen av sjöar med respektive utan ungar, tyder på att det finns miljövariabler som kan förklara både val av häckningsplats och häckningsutfallet, men förutom andel vegetation har vi fortfarande lite kunskap om andra möjliga variabler som påverkar val av häckningssjö och häckningsframgång i Västerbotten.

\section{Tack}

Studierna 2010-2015 genomfördes inom ramarna för en miljökonsekvensbeskrivning inför ett vindkraftsprojekt som planerades på Holmöarna vid denna tid, vilken finansierades av Energimyndigheten och Slite Vind. Studierna 2019 och arbetet med denna artikel har finansierats av Alvins fond. Ett stort tack till Mats O. G. Eriksson, Börje Dahlén och en anonym granskare för värdefulla kommentarer på artikeln. 


\section{Referenser}

BirdLife International. 2015. Gavia stellata (Red-throated Loon). European Red List of Birds. Supplementary material. Office for Official Publications of the European Communities. Tillgänglig från https://nature-art12.eionet.europa.eu/article12/ summary?period $=3$ \& subject $=$ Gavia + stellata.

BirdLife International. 2020. Species factsheet: Gavia stellata. http:// datazone.birdlife.org/species/factsheet/red-throated-loon-gaviastellata, nedladdad 3 March 2020.

Bundy G. 1976. Breeding biology of the Red-throated Diver. Bird Study 23: 249-256. https://doi.org/10.1080/00063657609476511

Dahlén B \& Eriksson MOG. 2002. Smålommens Gavia stellata häckningsframgång i artens svenska kärnområde. Ornis Svecica 12: 1-33. https://doi.org/10.34080/os.v12.22452

Eberl, C. \& Picman, J. 1993. Effect of nest-site location on reproductive success of Red-throated Loon (Gavia stellata). Auk 110: 436-444. https://doi.org/10.2307/4088408

Eriksson MOG. 2019. Projekt Lom 25 år. Nivåer och trender i storlommens och smålommens häckningsutfall 1994-2018. Sidorna 41-57 i Fågelåret 2018 (Bentz PG \& Wirdheim A, red). BirdLife Sverige, Halmstad.

Eriksson MOG. 202o. Projekt Lom: Inventeringarna 2019. Tillgänglig från https://cdn.birdlife.se/wp-content/uploads/sites/30/2020/02/ LOM-rapportering-2019.pdf.

Eriksson MOG \& Åhlund M. 2013. Dynamiken i smålommens Gavia stellata val av häckningslokaler - övergivande, ny- och återetableringar. Ornis Svecica 23: 130-142. https://doi.org/10.34080/ os.v23.22450

Västerbottens Ornitologiska Förenings rapportkommitté. 1990. Fåglar i Västerbotten. Supplement 3. 44 sidor.

Västerbottens Ornitologiska Förenings rapportkommitté. 1991. Fåglar i Västerbotten. Supplement 4. 40 sidor.

Green M, Haas F \& Lindström Å. 2020. Övervakning av fåglarnas populationsutveckling. Årsrapport för 2019. Biologiska institutionen, Lunds universitet. 96 sidor. Tillgänglig från https://www.fageltaxering.lu.se/sites/default/files/files/Rapporter/arsrapportfor2019kf. pdf.

Hemmingsson E \& Eriksson MOG. 2002. Ringing of Red-throated Diver Gavia stellata and Black-throated Diver Gavia arctica in Sweden. Wetlands International Diver/Loon Specialist Group News-letter 4: 8-13. Tillgänglig från http://projektlom.birdlife.se/wp-content/ uploads/sites/30/2018/10/Hemmingson-Eriksson-2002.pdf.

Hulka S. 2010. Red-throated Diver breeding ecology and nest survival on Shetland. Doktorsavhandling, University of Glasgow. 153 sidor. Tillgänglig från https://www.natural-research.org/application/files /7514/9073/4536/2010hulkaphd.pdf.

Häger A. 1968. Ornitologiska observationer på Holmöarna. Fältbiologerna, Umeå. 16 sidor.
Lehtonen E. 2016. Breeding site selection and breeding success in Red-throated Divers (Gavia stellata): Implications for wind power development. MSc thesis, Uppsala University. 54 sidor. Tillgänglig från https://www.diva-portal.org/smash/get/diva2:1072426/ FULLTEXTo1.pdf.

Lindblom H. 2003a. Projekt LOM i Södra Västerbotten. Fåglar $i$ Västerbotten 2003: 14-17.

Lindblom H. 2003b. Projekt LOM i Västerbottens kustland 2003. Fåglar i Västerbotten 2003: 97-98.

Lindblom H. 2004. Projekt LOM i södra Västerbottens kustland 2004. Fåglar i Västerbotten 2004: 102-103.

Länsstyrelsen i Västerbottens län 1974. Fåglar på Holmöarna. Inventeringsrapport. Umeå. 143 sidor.

Länsstyrelsen i Västerbottens län. 1997. Fåglar på Holmöarna. Inventeringsrapport. Umeå.

Länsstyrelsen i Västerbottens län. 2015. Naturreservat $i$ Västerbotten. Holmöarna. Tillgänglig från https://www.lansstyrelsen.se/ download/18.6a8f491016b944a8cbe2d5d3/1566911559847/ Holmo\%CC\%88arna\%2oSE.pdf.

Minitab 17 Statistical Software. 2010. Minitab Inc., State College, PA. Tillgänglig från https://www.minitab.com.

Okill JD \& Wanless S. 1990. Breeding success and chick growth of Red-throated Diver Gavia stellata in Shetland 1979-1988. Ringing \& Migration 10: 26-30. https://doi.org/10.1080/03078698.1990.9 673963

Olsson C. 1992. Inventering av Umeå kommuns sjöar. Fåglar $i$ Västerbotten 17: 86-116.

Ottosson U, Ottvall R, Elmberg J, Green M, Gustafsson R, Haas F, Holmqvist N, Lindström $\AA$, Nilsson L, Svensson M \& Svensson S. 2012. Fåglarna i Sverige - antal och förekomst. Sveriges Ornitologiska Förening, Halmstad. 592 sidor.

Pettersson J \& Olsson C. 2015. Kunskapsuppbyggnad för arterna smålom, storlom, havsörn och fiskgjuse och deras hemområden inför planerade vindkraftsetableringar - en studie utförd på Holmön, Umeå kommun, Västerbottens Län. Rapport på uppdrag av Uppsala universitet. 47 sidor.

Rizzolo DJ, Gray CE, Schmutz JA, Barr JF, Eberl C \& McIntyre JW. 2020. Red-throated Loon (Gavia stellata), version 2.o. I Birds of the World (Rodewald PG \& Keeney NK, red). Cornell Lab of Ornithology, Ithaca, NY. https://doi.org/10.2173/bow.retloo.02

Rizzolo DJ, Schmutz JA, McCloskey SE \& Fondell TF. 2014. Factors influencing nest survival and productivity of Red-throated Loons (Gavia stellata) in Alaska. Condor 116: 574-587. https://doi. org/10.1650/CONDOR-14-25.1

Skyllberg U, Lessmann J \& Hansson P. 1999. Häckningsmiljöns betydelse för häckningsframgången hos havsfiskande smålom Gavia stellata i Västerbotten. Ornis Svecica 9: 107-120. https://doi. org/10.34080/os.v9.22453

\section{English summary}

The aim of this study was to estimate the population size, breeding success, environmental factors affecting the breeding success, and the distance to fishing waters in the Red-throated Loon Gavia stellata (Figure 1) on the Holmöarna Archipelago in Kvarken, the northern part of the Baltic Sea, Sweden (Figure 2).

All of the 135 lakes on the archipelago's two largest islands, Holmön and Ängesön, were visited and surveyed for breeding Red-throated Loons at least three times annually during the breeding period between 2010-2015 and in 2019. The first visit was carried out in the period 15-25 May, when we searched intensively for 
Red-throated Loons until we could conclude whether the lake contained one pair (in a few cases two pairs) or no pair. If there was any uncertainty of the presence of Red-throated Loons in a specific lake, the lake was visited again later in May. A third visit was carried out 5-20 August to lakes where nesting birds had been found at one of the first two visits, or where no nest had been found but one or two adults had shown nervous behaviour, indicating active breeding. In addition, all lakes where small offspring (not exceeding two thirds of the size of an adult) were found at one of the first two visits were visited again in August. A successful breeding was defined as the offspring reaching a size exceeding two thirds of an adult, since predation of large young is rare.

In each breeding lake the following environmental variables were assessed to get an idea of characteristics of lakes selected for nesting: the size of the lake, the proportion of lake surface without vegetation, and the number of small and large islets in the lakes. In lakes where no Red-throated Loons were found, no environmental variable surveys were made.

To determine where the nesting birds' pelagic fishing areas in the Baltic Sea, we made systematic observations of foraging adults from the beginning of July to the beginning of August. One observer surveyed the birds in their breeding lake and another observer was situated at the coastline, waiting for a phone call from the lake observer, alerting that a Red-throated Loon had left the lake, and specifying its flight direction. The route between a breeding lake and fishing waters was usually the same.

We found that lakes with breeding Red-throated Loon pairs had an area of $0.3-6.4$ ha, with an average of 1.6 ha (Table 1 ). The proportion of the lake surface without vegetation cover was estimated to an average of $82 \%$ and there were on average 1.2 large and 3.6 small islets in the lakes (Table 1). During the seven years of study, the Red-throated Loon was found in 43 of the 135 lakes. The average number of offspring per breeding pair was 0.27 (Table 2). The average distance of pelagic foraging trips was $1.8 \mathrm{~km}$ (Figures 3-7), and the offspring were fed Atlantic herring Clupea harengus (Figure 8).

There was no significant correlation between breeding success and any of the environmental variables examined. However, we discuss the possibility that a higher proportion of surface vegetation cover might be favourable for breeding success. The most likely factor negatively affecting the breeding success of Red-throated Loons on the archipelago is avian predators, such as the Common Crane Grus grus and the White-tailed Eagle Haliaeetus albicilla. There were 96 breeding pairs of Common Crane in 2010 and eight breeding pairs of White-tailed Eagles in 2015. The number of breeding Red-throated Loon pairs was positively correlated with vegetation cover and distance to the sea.

The Red-throated Loon probably has a long history on the Holmöarna Archipelago, where it has been documented at least since the 1960 s. The first survey of the entire population was carried out in 1992, when 21 pairs were found. It was followed by a study of the entire population from 2001 to 2004, when 23-24 pairs were found. The Red-throated Loon is at the Swedish Red List of threatened bird species, but nevertheless the population on the Holmöarna Archipelago has grown since then. In summary, the Holmöarna Archipelago in the northern part of the Baltic Sea was found to be a stronghold for Red-throated Loon, with an estimated population of 25-35 pairs during the seven years of study (2010-2015 and 2019). The breeding success, however, seems to be low.

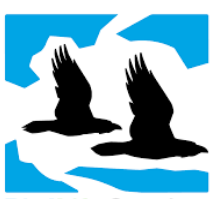

Birdlife Sverige

Ornis Svecica (ISSN 2003-2633) is an open access, peer-reviewed scientific journal published in English and Swedish by BirdLife Sweden. It covers all aspects of ornithology, and welcomes contributions from scientists as well as non-professional ornithologists. Accepted articles are published at no charge to the authors. Read papers or make a submission at os.birdlife.se.

Ornis Svecica (ISSN 2003-2633) är en fritt tillgänglig granskad vetenskaplig tidskrift som ges ut på svenska och engelska av BirdLife Sverige. Den täcker ornitologins alla områden och välkomnar bidrag från såväl forskare som icke-professionella ornitologer. Accepterade uppsatser publiceras utan kostnad för författarna. Läs uppsatser eller skicka in ditt bidrag på os.birdlife.se. 